\title{
Experimental investigation of a timber-concrete floor panel system with a hybrid glass fibre reinforced polymer-timber corrugated core
}

\author{
Ya Ou a , Joseph M. Gattas a , Dilum Fernando ${ }^{\text {a, }}{ }^{*}$, José L. Torero $^{\mathrm{b}}$ \\ a School of Civil Engineering, University of Queensland, Australia \\ ${ }^{\mathrm{b}}$ Department of Civil, Environmental and Geomatic Engineering, University College London, United \\ Kingdom \\ *Corresponding author. E-mail address: dilum.fernando@uq.edu.au (D. Fernando).
}

\begin{abstract}
Hybrid timber-concrete (HTC) floor systems are well-suited for prefabricated construction and so have seen widespread use in modern sustainable buildings. This paper investigates a novel extension to such systems by introducing a corrugated core between tensile timber and compressive concrete layers. This new "HTCC" floor panel system is hypothesised to have an increased weight-specific flexural capacity relative to HTC systems, by reducing the volume of concrete below the panel neutral axis without decreasing flexural capacity. This paper experimentally investigates the flexural performance of the new system, acting in two configurations: with core orientation parallel to the span for maximum longitudinal one-way spanning capacity; and with core orientation transverse to the span for generation of a novel transverse spanning capacity. In total, eight HTCC floor panels were prepared and tested, with the flexural capacities and critical failure modes analysed for each. Effects of different core geometries, shear force transfer methods, and manifested composite action are also closely studied. Longitudinal specimens achieved the best composite action and correspondingly the highest panel performance, with a 73\% ultimate moment carrying efficiency and an 85\% stiffness efficiency at SLS, compared to an idealised HTC section with full composite action.
\end{abstract}

Keywords: Composite structure; GFRP-timber corrugated core; Hybrid timber-concrete floor panel 


\section{Introduction}

Hybrid timber-concrete (HTC) floor panels are a lightweight and sustainable alternative to conventional reinforced concrete floor systems [1]. They have been used on a number of recent projects, including new construction [2], refurbishment of old timber floors [3-5], and as bridge decks [6-9]. HTC floor panels consist of a timber layer acting as the tensile reinforcement and a concrete layer acting as the compression element, with composite action achieved through the bi-material interface by adhesive bonding or mechanical anchoring $[2,10]$. The panels are economical to construct as they can be entirely or partially pre-fabricated [11], with the latter case having timber fabricated off-site and installed onsite as permanent structural formwork for concrete casting.

The flexural behaviours of HTC floor panels have been characterised through extensive testing of full-scale specimens [12-19]. These studies have shown that HTC floor panels have a higher load carrying capacity and out-of-plane rigidity compared to the traditional timber floor systems [20, 21] and a higher load-to-weight ratio than reinforced concrete floor panels [21]. Experimental studies have also revealed that perfect composite action between concrete and timber is difficult to achieve, with shear slip at the timber-concrete bi-material interface having a substantial effect on panel stiffness and strength $[15,22]$. Of shear connectors types investigated for HTC systems, adhesive bonding provides the highest composite action $[1,10]$, however the key problem with most connector types is that the timber-concrete interface is located below the neutral axis; when slip occurs, concrete is subjected to high tensile stress and interfacial connectivity is reduced as cracking develops. This contributes to further shear slip and tensile concrete stresses; which leads to a significant volume of cracked concrete which contributes little to panel flexural capacity.

This paper investigates the flexural behaviour of a novel hybrid HTC floor panel which introduces a corrugated core layer as shown in Fig. 1. The "HTCC" panel is hypothesised to reduce the tensile concrete inefficiencies exhibited by conventional HTC panels (Fig. 2a), for an improved overall loadto-weight flexural capacity. Sections 2 first describes the design, geometric details, and fabrication of 
specimens. Section 3 then presents the experimental program and test results, including loaddisplacement behaviour, failure modes, and composite action. Section 4 assesses the experimental results and the performance of the HTCC panels and compares with the idealised HTC systems with full composite action.

\section{Floor panel design and fabrication}

\subsection{Core geometry and material selection}

The key innovation proposed in the HTCC system is the introduction of an additional core layer which can reduce the volume of concrete under the neutral axis, without negatively effecting panel flexural capacity. A corrugated pattern was selected as the core shape with these characteristics, as shown in Fig. 1. Voids below the core are left hollow, reducing concrete volume and providing a potential conduit for building service cables. With reference to Fig. 2a-b, the core corrugation introduces two interfaces in place of the single concrete-timber interface in HTC systems, with core-timber and concrete-core interfaces along corrugated valley and ridge surfaces, respectively.

The concrete-core ridge interface is above the neutral axis to minimise loss of composite action through tensile cracking in the concrete, however core material choice will have a strong impact on the overall composite action manifested by the HTCC system. A GFRP-timber laminate was chosen as the core material as it is economical and easy to manufacture, has mechanical properties significantly above a pure timber structure, and has a reduced weight and carbon intensity as compared to a steel material [23-26]. More importantly, it can act as a waterproof layer to protect the timber from the moisture introduced by concrete casting and can allow a strong bonded connection between the core and timber layers.

\subsection{Core and panel dimensions}

The core and panel dimensions in an initial HTCC specimen were designed to ensure two criteria are met: (a) the concrete volume was reduced by at least $40 \%$ compared with an HTC panel section of 
the same overall height; and (b) the neutral axis of the section remained within the core so the top concrete acted predominantly in compression. Selected specimen cross sectional dimensions are shown in Fig. 2c. The total height of the specimen was $160 \mathrm{~mm}$ which was consistent with similar existing experimental studies of HTC floor panels $[15,17]$. Core height, ridge length, and valley length dimensions gave a $47 \%$ reduction in concrete weight compared a HTC specimen of the same height.

The section neutral axis was calculated from a section analysis to be $55.6 \mathrm{~mm}$ below the top surface, placing the concrete-core interface and concrete volume predominantly in compression. The section analysis assumed failure was controlled by the tensile timber failure. Linear elastic material properties were assumed for tensile timber and plywood, with fibre direction elastic moduli of $12.7 \mathrm{GPa}$ and 10.5GPa [27], respectively. Concrete compressive strength was assumed at this first design stage as $35 \mathrm{MPa}$ with the compressive stress-strain relationship provided by Eurocode 2 [28] and concrete tensile strength assumed to be negligible.

A preliminary finite element (FE) analysis was used to design the corrugated core material thickness to ensure core failures, including buckling and crushing, did not occur in the core prior to the ultimate load calculated from the section analysis. A three-layer $7 \mathrm{~mm}$ plywood thickness and $1025 \mathrm{gsm}$ unidirectional GFRP face thickness were found to be adequate for this, with the fibre direction of the GFRP was parallel to the panel axis and the grain direction of the plywood face layers orthogonal to the panel axis. Complete model details and assumptions are described in Appendix A.

\subsection{Transverse core variations}

The above HTCC design introduced a core orientation aligned with panel span direction. There was no continuous fibre (timber or GFRP) in the direction orthogonal to the span axis for carrying flexural loads, so it can only be used as one-way spanning slab as is typical for HTC systems. This design is termed the Longitudinal Core "LC" panel type, with two specimens manufactured for testing as described in the next section. 
The inclusion of a core layer however introduces a novel potential for transverse load carrying capacity in HTCC slabs. Consider a "Base Core" (BC) configuration, designed with similar dimensions as LC panels, but with core orientation altered to give continuous GFRP and timber fibres alignment as shown in Fig. 3 and Fig. 4a. Continuous tensile fibres in the span direction would be expected to give a significant transverse load carrying capacity, while preserving other key benefits of the HTCC system: a concrete volume reduction, ease of manufacture, and hollow conduits for building services.

However, when the core is orthogonal to the panel span, the bond line between the core and tensile timber is discontinuous, which is likely to result in stress concentration at the edges of core valley plates, and has lower bond area. This introduces a high risk of debonding failure at the interface between core valley and tensile timber. To investigate the behaviour of transverse HTCC panels and navigate the potential sensitivity of interfacial behaviour between core and the tensile timber, two BC specimens were manufactured with different core-timber interfacial connectivities: one with direct bonding only, and one with bonding and additional shear bolt reinforcement.

Interfacial shear behaviour can also be modified with adjustment to the core geometry itself, which gives an additional designer ability to control or modify panel performance. Two additional core configurations were designed to investigate this. "High Core" (HC) specimens had the same valley and ridge plate sizing as $\mathrm{BC}$ but with the core height increased to $120 \mathrm{~mm}$, increasing the second moment of inertia as shown in Fig. 4b. "Skinny Core" (SC) specimens were designed with the same core height and ridge plate size as the $\mathrm{BC}$ design, but with a lower timber-core shear capacity within each corrugated unit, from reduced valley plate sizing as shown in Fig. 4c. Again, two specimens of each type were manufactured, one with and one without shear bolt reinforcement.

To summarise, eight HTCC specimens were designed with properties as listed in Table 1. To provide a consistent naming, each specimen is designated with a four-letter name. The first two letters indicate the type of core used: LC, BC, HC, or SC. The third character consists of either number "1" or "2" to differentiate between two identical core type specimens, while the fourth character is used to 
identify if the shear bolt reinforcement was used ("D") or not ("P”). For example, HC2D is a panel with a high core and shear reinforcement. Table 1 also lists the weight of each specimen. For transverse specimens, the concrete volume reduction as compared with a typical HTC section with the same total section height and timber thickness was $42 \%$ for $\mathrm{BC}, 44 \%$ for $\mathrm{HC}$ and $51 \%$ for SC designs.

\subsection{Panel dimensions and materials}

All the specimens in this study were designed with a consistent panel length, panel width, concrete depth above the core ridge, and tensile timber thickness. Overall panel size was $570 \mathrm{~mm}$ wide and $2400 \mathrm{~mm}$ long. Total section height was $160 \mathrm{~mm}$ for LC, BC, and SC panel types, and 190mm for HC panel types.

Concrete used in all the specimens were from the same batch and with an average 28-day compressive strength of $41.9 \mathrm{MPa}$, as determined from three concrete cylinder samples according to Australian Standard AS1012.9 [29]. The corrugated core was composed of a GFRP-timber-GFRP laminate, consisting of a $7 \mathrm{~mm}$ plywood board (three-layer fibre) bonded with a layer of $1025 \mathrm{gsm}$ uniaxial GFRP fabric on each face. Commercially-available polyurethane adhesive Purbond was used for bonding GFRP fabric to plywood within the core and for bonding the corrugated core to tensile timber. Polyurethane type adhesive was selected because of its high performance in moist environments [30], as the concrete casting was expected to introduce high moisture content to the bonded interfaces. Tensile timber layer was formed of three pieces of $35 \mathrm{~mm}$ thick, $190 \mathrm{~mm}$ wide pine wood boards with grain direction parallels to the panel axis, and boards had structural grading of MGP12, in which MGP represents machine graded pine as per Australian Standard AS1748 [31]; MGP12 indicates a minimum threshold for stiffness of $12 \mathrm{GPa}[27,31]$.

In all the specimens, $10 \mathrm{~g}-8 \times 100 \mathrm{~mm}$ chipboard screws were driven approximately $45 \mathrm{~mm}$ into the core and tensile timber at a $150 \mathrm{~mm}$ spacing along core valleys, to prevent the potential peeling failures at the concrete-core interface. Some reinforcement was also added along the panel support lines for HC and SC core types, with the two end voids filled with grout as shown in Fig. $4 \mathrm{~b}$ and c. This was to 
eliminate the concrete tensile failure occurring above the core ridge, observed during initial testing of the base core specimen BC2D, which will be further discussed in Section 3.3.

\subsection{Panel fabrication}

The manufacturing process of the specimens is briefly presented in this section, with complete details available in [32]. The GFRP-timber core laminates were first fabricated to the desired corrugated shape using compression moulding [25] and vacuum bagging [33] techniques (Fig. 5a). After the core was fully cured, it was bonded to the tensile timber and loaded during curing; when the timber-core bond was fully cured, chipboard screws were driven into the core and tensile timber (Fig. 5b). Concrete was cast into plywood formwork and cured in outdoor conditions for a minimum of 28 days (Fig. 5c). For one of the two transverse core specimens, after the concrete was fully cured, the $103 \mathrm{~mm}$ long M8 DP10100 Ramset ${ }^{\mathrm{TM}}$ DynaBolts were installed from tensile timber bottom surface into the concrete valley region following the procedure described in [34] (Fig. 5d). Finally, for SC and HC specimens, the first void at each end of the panel was filled with grout and left to set for a minimum of 5 days. Qualitatively, the manufacturing method was found to be easy, low cost, and provide very good quality specimens based on visual inspection.

\section{Experimental test and results}

\subsection{Testing method and instrumentation}

All specimens were tested under four-point bending, with a schematic test setup shown in Fig. 6 . Load was applied using a $1 \mathrm{MN}$ servo hydraulic MTS machine with displacement control at a rate of 2 mm per minute. A spreader beam was used under the MTS crosshead to apply two line loads on the specimen. The clear span between supports was $2200 \mathrm{~mm}$ and the distance between two loading lines was $640 \mathrm{~mm}$.

To capture the vertical deformation of the panel, four linear position transducers LP1-LP4 were used. To measure the relative slip between the tensile timber and the concrete block, two linear variable 
displacement transducers (LVDTs) LVDT1 and LVDT2 were placed at panel ends. To measure the strain distribution of mid-span regions, a digital image correlation (DIC) system was used to measure a region with width varying from $340 \mathrm{~mm}$ to $500 \mathrm{~mm}$, shown in Fig. 6. Finally, strain gauges were placed at the concrete top and timber bottom surfaces around mid-span to measure the axial strain in different layers. For longitudinal type specimens, strain gauges were only installed at the mid-span section, and for transverse type specimens, strain gauges were installed at both mid-ridge and mid-valley sections.

\subsection{Load-displacement behaviour}

The obtained specimen load versus mid-span deflection curves are shown in Fig. 7. Key load values are summarised in Table 2 at both the ultimate load state (ULS) and the serviceability limit state (SLS), taken at a mid-span displacement of 7.3mm (span/300) [35]. For Fig. 7, the left-hand side vertical axis shows the total load, while the right-hand side vertical axis shows the equivalent uniformly distributed load (UDL), with equivalency defined for a UDL to give the same maximum bending moment as the concentrated load.

Looking at specimen behaviour up to the ULS, significant variation in load capacity is seen between specimens, corresponding to each of the variations introduced for core orientation, transverse interfacial shear reinforcement, and transverse core geometry:

(a) Core orientation: Longitudinal-cored specimens LC1P and LC2P showed the highest ultimate load of all tested specimens $(71.7 \mathrm{kN}), 57 \%$ higher than the nearest transverse core with similar height, BC1P $(45.7 \mathrm{kN})$. However, LC cores only had a 3\% higher capacity compared to the bestperforming transverse core specimen, $\mathrm{HC} 2 \mathrm{D}(69.9 \mathrm{kN})$. The transverse core additionally showed a higher deformation capacity at failure $(84.7 \mathrm{~mm})$ compared to that of LC specimens $(60.6 \mathrm{~mm}$ and $44.9 \mathrm{~mm})$. These results indicate that while one-way spanning LC specimens are the most efficient HTCC configuration, HTCC systems with transverse core are able to introduce transverse loading capacity without significantly compromising the longitudinal loading capacity. 
(b) Transverse interfacial shear reinforcement: DynaBolt-reinforced transverse specimens BC2D and HC2D and SC2D showed $9.2 \%, 86.2 \%$ and $19.7 \%$ higher load carrying capacity than their counterparts without DynaBolts. Non-reinforced specimens showed a highly ductile response, undergoing a very large deformation without significant load decrease. These results indicate that enhancing the interlayer shear force transfer has significant positive effects on the load carrying capacity of the transverse-cored specimens, likely due to the increased composite action between the layers.

(c) Transverse core geometry: Comparing transverse specimens with different core geometries, highcored HC2D and skinny-cored SC2D showed 18 20\% higher weight-specific capacity than the base-cored $\mathrm{BC} 2 \mathrm{D}$. For $\mathrm{SC}$ specimens, results indicate performance improvement is mostly attributed to decreasing the weight of non-performative concrete. For HC specimens, performance improvement is primarily seen in Dynabolt-reinforced specimens and attributed to the efficiency of deeper section size. SC1P also achieved an $8 \%$ higher capacity than BC1P, which can be attributed in part to lack of grout filling in the BC1P specimen.

Looking at load-deflection behaviour up to the SLS in Fig. 7b, all curves were initially approximately linear. Longitudinal-cored specimens showed the highest initial stiffness among all specimens because of the constant section along the span, resulting in a higher overall second moment of area than the other specimens. DynaBolt-reinforced specimens BC2D, HC2D, and SC2D showed higher initial stiffness compared to their counterparts BC1P, HC1P, and SC1P, as DynaBolts effectively reduced the shear slip between the core and tensile timber layers. This will be investigated more closely in Section 3.3. When comparing the core geometry among the transverse-cored specimens, HC specimens had the highest stiffness because of their deep section height, BC specimens had a slightly lower stiffness, while the SC specimens had a lower stiffness than both, particularly for reinforced specimens. The reduced bonding area within each corrugated unit and higher cross-section variation along the span may have contributed to a higher slip and a corresponding stiffness reduction in SC 
specimens. SC specimens also have the lowest flexural stiffness of tested panels, thus the lowest interfacial slip compared to $\mathrm{HC}$ and $\mathrm{BC}$ specimens. The introduction of DynaBolts is therefore likely to have a reduced effect on the SC response within the early loading stages.

\subsection{Failure modes}

The failure modes of each core type were closely documented to establish how they contributed to the flexural performances observed above. Fig. 8 shows the following failure modes observed during the tests:

i. Debonding at the (a) corrugated core-tensile timber interface (F1), (b) concrete-corrugated core interface (F2), and (c) GFRP-plywood bi-material interface within the core (F3).

ii. Concrete cracks developed from core corner regions (d) between loading points (F4), (e) between supports and loading points (F5), and (f) longitudinal cracking (F6).

iii. Other concrete cracking: (g) flexural cracks in the region between loading points in longitudinal specimen (F7), (h) flexural-shear cracks in the regions between supports and loading points in longitudinal specimen (F8), (i) top surface cracking above the supports (F9), and (j) surface cracking near the grout-filled voids (F10).

iv. Material failures including (k) timber tensile rupture failure (F11), and (l) concrete crushing at the top surface between loading points (F12).

Load-displacement curves, interfacial shear slip curves, and failure modes of LC1P and LC2P are as shown in Fig. 9. Specimens had good consistency and repeatability of behaviour, which gives confidence to the validity of data collected for the individual specimens tested for each of the transversecore configurations. Due to consistency between LC specimens, only LC1P is discussed henceforth. Concrete flexural-shear cracks initiated between supports and loading points (F8, Fig. 9d) at mid-span deflection of $6.6 \mathrm{~mm}$. Vertical flexural cracks appeared between the loading points (F7, Fig. 9c) at deflection of $16.8 \mathrm{~mm}$ and fully developed across the height of the concrete layer, becoming the dominant failure. A clear longitudinal crack (F6, Fig. 9e) was also observed when the displacement was 
about $38.0 \mathrm{~mm}$. The measured slip between concrete and tensile timber at the panel ends were found to have a similar trend until about $40 \mathrm{~mm}$ deflection, indicating symmetry of the interface behaviour at initial stages. This symmetry was however lost beyond 40mm mid-span deflection and as the ultimate load is reached, with at maximum end slip of approximately $8-17 \mathrm{~mm}$.

Looking next at the transverse specimens, load-displacement curves, interfacial shear slip curves, and failure modes of base-cored specimen with no shear reinforcement (BC1P) shown in Fig. 10. Interfacial shear deformations (failure mode F1, Fig. 10c) started at mid-span deflection of 7.4mm, full debonding of the concrete core from the corrugated plate was observed at one end of the specimen (F2, Fig. 10d) when deflection was about $59.2 \mathrm{~mm}$, and debonding at the GFRP-plywood bi-material interface (F3, Fig. 10e) started at deflection 10mm. Cracks started to appear from corrugation corners between loading points and supports (F5, Fig. 10g) when deflection was $13.7 \mathrm{~mm}$, and cracks happened between the two loading points (F4, Fig. 10f) at deflection $59.2 \mathrm{~mm}$. Ultimate failure occurred at a deflection of $94.7 \mathrm{~mm}$ due to fully developed cracks in F4 and F5, with subsequent deflection leading to timber tensile rupture failure (F11, Fig. 10h) at deflection $123.8 \mathrm{~mm}$. Shear slip values are plotted in Fig. $10 \mathrm{~b}$ and show that values at each end are similar to each other, remain low up to the SLS, and then increase rapidly to ULS, ended at about $24-28 \mathrm{~mm}$ at both ends, which were much larger than the LC type specimens.

Shear reinforced specimen BC2D failure data is also shown in Fig. 10 for comparison to its counterpart BC1P. Initial failure was observed as cracking on the concrete surface above one support (F9, Fig. 10i) at deflection $9.2 \mathrm{~mm}$, which then grew to become a fully developed across the width of the panel. F5 cracking (Fig. 10j) appeared from $25.8 \mathrm{~mm}$ and fully developed across the height of concrete layer, until causing ultimate failure at deflection of $35.4 \mathrm{~mm}$. Shear slip values as plotted in Fig. $10 \mathrm{~b}$, captured only at one end due to equipment malfunction, show a positive then negative slip due to movement of the end concrete block from F9. Comparing between BC1P and BC2D, DynaBoltreinforcement effectively suppressed debonding failures F1, F2 and F3. 
The initial F9 failure of specimen BC2D occurred directly above the void in the end support region (Fig. 10i). For this reason, subsequent high-cored and skinny-cored samples had grout-filled end voids to provide support line reinforcement. HC2D and SC2D failure modes and responses are shown in Fig. 10 and it was seen that F9 was suppressed for both HC2D and SC2D. Initial failure was F5 at mid-span deflection of $10.7 \mathrm{~mm}$ and $4 \mathrm{~mm}$ for $\mathrm{HC} 2 \mathrm{D}$ and SC2D, respectively. For HC2D, these cracks then developed between corrugated corners (Fig. 11c), rather than across the height of the concrete layer as seen previously in BC1P specimens (Fig. 10g), until full separation of the top concrete layer occurred at deflection $88.7 \mathrm{~mm}$. A concrete crack emerged above the corrugation corner beside one filled void (F10, Fig. 11d) at deflection $11.5 \mathrm{~mm}$, however this crack did not develop to the full depth of the ridge before the end of the test. For SC2D, F5 cracks developed parallel to the panel axis and through the depth of the concrete layer (Fig. 11e). F10 again occurred early, at deflection of $16.6 \mathrm{~mm}$, but did not fully develop. Crushing at the top surface of the concrete (F12, Fig. 11f) also occurred between loading points when deflection reached $75.1 \mathrm{~mm}$.

The results of shear reinforced and non-reinforced HC and SC types are similar to that for BC types, although F2 and F3 did not occur in $\mathrm{HC} 1 \mathrm{P}$ or SC1P, with the former suppressed by end void filling and the latter suppressed with improved manufacturing and a better bond quality between GFRP and plywood. Slip values for HC2D and SC2D are shown in Fig. 11b and slip again developed more quickly after reaching SLS, but with low final end slip for both specimens (less than $10 \mathrm{~mm}$ ) as compared to unreinforced specimens.

\subsection{Axial strain distribution through panel depth}

Panel axial strain distribution was analysed from the collected DIC data. In the transverse pattern specimens, one ridge section and one valley section near mid-span (Fig. 12a) were chosen to show the through depth strain distribution, while in longitudinal specimens only the mid-span section (Fig. 12b) was analysed because of the constant section along the span. Strain distributions at the SLS and ULS are given in Fig. 13 for one longitudinal-cored specimen (LC1P) and two transverse-cored specimens 
(HC1P, HC2D). In Fig. 13, y=0 represents the top surface of the concrete and $y=-160$ (Fig. 13a) or $y=-$ 190 (Fig. 13b-e) represents the bottom surface of the timber. Top and bottom surface strain gauge (SG) readings are also shown in Fig. 13 and show good correlation with DIC values.

In the longitudinal pattern specimen LC1P (Fig. 13a), strain within concrete was nonlinear. Concrete above the corrugated core ridge surface was under compression at both the SLS and ULS stages, though part of the concrete within the core height was in tension. The timber layer was under tension at the SLS stage, which indicates high composite action was achieved in LC1P until SLS. However, at the ultimate stage, upper part of the timber was under compression because of the loss of composite action. For HC1P and HC2D in Fig. 13b-e, it can be found that the concrete strain within the valley section (Fig. 13b and d) showed high nonlinearity along the section height, especially in DynaBolt-reinforced HC2D. Concrete strain in the ridge section (Fig. 13c and e) distributed approximately linearly above the core. Until the SLS, concrete and timber layers acted predominantly in compression and tension respectively. Though some tension was observed in HC1P within concrete at SLS, the region of concrete acting in tension was negligible in HC2D. This indicates high composite action achieved in HC2D until SLS. However, at the ULS, both concrete and bottom timber showed tension and compression regions, again indicating the reduction of composite action.

In all the specimens, there were strain differences at the bi-material interface and this difference increased from SLS to ULS. This again indicates the reduction of composite action in the panels. Meanwhile, it can be noticed that the maximum compressive strains on top surface of the concrete in HC2D (Fig. 13d and e) and LC1P (Fig. 13a) were higher than that in HC1P (Fig. 13b and c), indicating a greater concrete utilization in the former two specimens.

\section{Discussion}

\subsection{Critical failure modes}

Two failure modes dominated HTCC floor panel performance: concrete cracking initiated at the corrugated core corners and interfacial shear slip between the corrugated core and tensile timber. In all 
the specimens, cracks at corrugated corners were observed during early stages of loading, and fully developed towards the ultimate state. For specimens with transverse core geometries, these cracks were shown to affect the load carrying capacity of the specimens, especially resulting in loss of composite action due to discontinuities. Initiation of the cracks correspond to stress concentrations at the corrugation corners as seen for example in Fig. 12a. Such stress concentrations could be reduced with smoother corners, which could potentially delay the cracking of concrete.

Large interfacial shear deformations were observed in transverse cores with no DynaBoltreinforcement, but this deformation was suppressed with the addition of the interlayer DynaBolt reinforcement. These reinforced specimens had increased stiffness, load carrying capacity and concrete use compared to their non-reinforced counterpart, due to the higher composite action achieved by the reinforced interface. In contrast, longitudinal panels showed a similarly high stiffness and strength without DynaBolt-reinforcement, as the continuous bonding interface allowed more effective shear force transfer compared to the discontinuous bond lines in the transverse-cored specimens.

\subsection{Variations in flexural behaviour}

Strain distribution results show that the flexural behaviour of HTCC floor panels varied between SLS and ULS states and, in transverse cases, varied between mid-ridge and mid-valley regions. High composite action was observed until SLS, indicating the initial design methodology based on section analysis assuming perfect composite action was valid up to SLS. This also indicated that concrete will not crack at the interface between the core and concrete until SLS, which is important to the long-term behaviour of the HTCC panels.

As the load increased past SLS, reduction of composite action was seen as evidenced by strain discontinuities between layers and concrete and timber being subjected to both tensile and compressive stresses, respectively. Cracking of concrete and shear slip at the corrugated core-tensile timber interface was observed as the load increased past SLS and reduced panel composite action and flexural capacity. Reduction in slip at the corrugated core-tensile timber through the use of DynaBolts was seen to enhance 
the composite action between the layers and the flexural capacity of the panels. Nevertheless, highly nonlinear strain distributions across the height of the specimens were observed beyond SLS loads and indicate that a section analysis based on linear strain distribution cannot accurately predict the ultimate flexural capacity.

For transverse core specimens, strain distribution across the height was found to be different between the mid-valley and mid-ridge regions. At ULS, concrete strain variations across the height of mid-valley regions were highly non-linear, while strain distribution across the height of concrete in midridge regions were found to show much less nonlinearity. The location of zero strain was also found to vary between adjacent mid-valley and mid-ridge regions. This change in zero strain location indicates the uneven distribution of moment of inertia along the length, which results in localized moments and crack initiation at corner regions. Similarly, at the end regions, this change in section moment of inertia results in hogging moments in concrete, thus creating tensile cracking in top concrete.

\subsection{Effectiveness of the GFRP-timber corrugated core}

Manufacturing of the GFRP-timber core was found to be easy and cost effective, with no core timber failures observed in any of the tested HTCC specimens. The transverse-cored specimens without DynaBolt-reinforcement had failure at the bonded interfaces, which showed that reduced length of bonding between the core and tensile timber was not capable of fully transferring the shear force at bimaterial interfaces. However, interfacial shear transfer was significantly improved with the use of DynaBolts. LC1P and LC2P specimens also showed a significant improvement in the interfacial shear transfer compared to the transverse core specimens with no shear bolt reinforcement. Overall, it can be concluded that the corrugated core can effectively transfer shear forces between the layers if adequate bond length is provided, as in the case of longitudinal core specimens. For the core to be effective in transverse core systems, it is necessary to provide DynaBolts to reinforce the core in interfacial shear transfer. 


\subsection{HTCC performance relative to HTC systems with full composite action}

The performance of the HTCC systems proposed is compared with the similar HTC sections (570mm width, $35 \mathrm{~mm}$ thick timber together with solid concrete of $125 \mathrm{~mm}$ or $155 \mathrm{~mm}$ height) with full interlayer composite action. Companion is made in terms of moment capacity and stiffness efficiency (Table 3). The stiffness efficiency is defined by Eq. (1) [15]. In (1), $D_{c}$ is the theoretical deflection with full composite deflection, $\mathrm{D}_{\mathrm{N}}$ is the theoretical deflection with no composite deflection, and $\mathrm{D}_{\mathrm{I}}$ is the measured deflection of the test specimens.

$$
\text { Efficiency }=\frac{\left(D_{N}-D_{I}\right)}{\left(D_{N}-D_{C}\right)} \times 100 \%
$$

The moment capacity of sections with full composite action is calculated using a section analysis with the material properties listed below, the results are as listed in Table 3. The detailed calculation methods of deflections $\left(\mathrm{D}_{\mathrm{N}}, \mathrm{D}_{\mathrm{C}}\right)$ and the moment capacity $M_{\text {full }}$ in Table 3 are documented in Appendix B.

(a) Concrete compressive stress-strain behaviour was assumed according to the specifications given in Eurocode 2 [28], with 28-days mean compressive strength of 43MPa (based on the concrete cylinder test data);

(b) Concrete tensile strength was assumed to be negligible; and

(c) Linear-elastic stress-strain behaviour for timber as described in AS1720 [27], with a characteristic tensile strength of $12 \mathrm{MPa}$.

Compared to similar HTC systems with full composite action, HTCC specimens achieved between $30 \%-73 \%$ moment capacity efficiency. LC specimens achieved $73 \%$ of the capacity of sections with full-composite action, demonstrating the relatively high efficiency of those specimens in terms of resisting interfacial slip and material usage compared to other types of specimens tested in this study. DynaBolts effectively reduced the shear slip in reinforced transverse specimens, but their achieved 
maximum moment capacity was still only $51 \%-56 \%$ of that of a section with full composite action, limited by the concrete cracks in the specimens.

In terms of the efficiency at SLS, all specimens showed higher efficiencies than at the ultimate stage (51\%-85\%), showing that higher composite action was maintained at this stage. Longitudinal specimens still had the highest efficiency at SLS (84\% and 85\%) and transverse specimens with DynaBolt reinforcement had slightly higher efficiency than their counterparts.

\section{Conclusions}

This paper has investigated the flexural performance of a series of eight novel hybrid timberconcrete floor deck with a corrugated GFRP-timber core. These novel HTCC panels reduced the concrete usage by $42 \%-51 \%$ compared to similar HTC panels with the same concrete and timber height. From test results, the following conclusions could be drawn:

(a) The corrugated GFRP-timber core is an economical, easy to manufacture system which provides effective interlayer connectivity in HTCC panels, provided sufficient bond area or additional shear reinforcement exists to transfer interfacial shear loads.

(b) The corrugated core orientation had a strong effect on the load carrying capacity of the HTCC specimens. In the four tested core geometries, longitudinal core specimens showed the highest weight-specific load carrying capacity. They also showed a $73 \%$ ultimate moment carrying efficiency and an 85\% stiffness efficiency at SLS, compared to an idealised HTC section with full composite action.

(c) For transverse core specimens, inclusion of DynaBolt-reinforcement significantly reduced the interfacial slip and increased panel moment capacity, with reinforced specimens achieving 9.2\%$86.2 \%$ higher load carrying capacity as compared to their counterparts without shear reinforcement.

(d) Decreasing the width of core corrugations reduced the non-performative concrete under neutral axis and so increased the panel weight-specific capacity. However, as it also reduced the bonding 
area within each core corrugation unit, the initial stiffness of the panel was also reduced, which was not desired.

(e) Increasing the core height and introducing DynaBolt interfacial shear reinforcement increased the stiffness and the strength of transverse core panels. Such specimens were shown to possess a similar performance to longitudinal core specimens.

\section{Acknowledgement}

The authors would like to thank Hyne Timber Pty Ltd. for donating the tensile timber used in this study and technical staff at the University of Queensland for their assistance in carrying out experimental tests. The first author is also grateful for the financial support received from China Scholarship Council, and the second and third authors are grateful for the financial support received from Australian Research Council Discovery Project funding scheme [grant number DP160103279].

\section{Appendix A. Details of the finite element model for the core design}

To check the performance of the core, a preliminary 3D finite element model of the HTCC floor panel was developed using commercially-available software ABAQUS. Concrete was modelled using general purpose brick element C3D8R. Constitutive behaviour of the concrete was modelled using concrete damaged plasticity model available in ABAQUS [36]. Concrete compression strength was assumed to be $35 \mathrm{MPa}$, while elastic modulus and the stress-strain data were calculated based on Eurocode 2 [28]. Shell element S4R was used to model the plywood and GFRP layers in the core and the tensile timber layer. Timber and GFRP layers were modelled as orthotropic linear elastic material. Elastic modulus of timber parallel to grain $\left(E_{1}\right)$ was assumed to $12.70 \mathrm{GPa}$, while elastic modulus in tangential $\left(E_{2}\right)$ and radial $\left(E_{3}\right)$ directions were assumed to be $0.99 \mathrm{GPa}$ and $1.44 \mathrm{GPa}$ respectively. Shear modulus in different directions were assumed to be $G_{12}=1041 \mathrm{MPa}, G_{13}=1028 \mathrm{MPa}, G_{23}=165 \mathrm{MPa}$ while Poisson's ratios were assumed to be $v_{12}=0.292, v_{13}=0.328, v_{23}=0.362[27,37]$. Elastic modulus of GFRP in fibre direction $\left(E_{1}\right)$ was assumed to be $44 \mathrm{GPa}$, while elastic modulus in other two principal directions 
(i.e. $E_{2}$ and $E_{3}$ ) were assumed to be $11 \mathrm{GPa}$. Shear modulus of GFRP in different directions were assumed to be $G_{12}=G_{13}=4.5 \mathrm{GPa}, G 23=0.5 \mathrm{GPa}$, while Poisson's ratios in different directions were assumed to be $v_{12}=v_{13}=0.28, v_{23}=0.1$ [38]. Considering the high strength of GFRP compared to timber, failure of GFRP was ignored. Timber failure was modelled using well-known Hashin failure criterion [39]. The longitudinal tensile, compressive and shear strengths of timber was assumed to be $20.4 \mathrm{MPa}, 40 \mathrm{MPa}$, and 5.6MPa, while transverse tensile, compressive and shear strength of timber was assumed to be $0.8 \mathrm{MPa}, 17 \mathrm{MPa}$ and $5.6 \mathrm{MPa}[27,40]$. All bonded interfaces were modelled using tie constraints assuming a perfect bond.

\section{Appendix B. Deflection and moment capacity calculation of the hybrid timber concrete panels in}

Table 3

\section{B.1. Deformation at SLS}

Deformation of a beam under four point bending as shown in Fig. A1 is calculated by [41]:

$$
\begin{aligned}
D(x) & =\frac{P(L-a)}{6 L E I}\left[\frac{L}{L-a}(x-a)^{3}-x^{3}+\left(L^{2}-(L-a)^{2}\right) x\right] \\
& +\frac{P a}{6 L E I}\left[\frac{L}{a}(x-(L-a))^{3}-x^{3}+\left(L^{2}-a^{2}\right) x\right]
\end{aligned}
$$

In this case, the deformation of an HTC beam with no composite action $\left(D_{N}\right)$ and full composite action $\left(D_{C}\right)$ can be calculated by replacing $E I$ in Eq. (A3) to be the bending stiffness of a beam with no

composite action $(E I)_{0}=E_{c} I_{c}+E_{t} I_{t}$, or with full composite action $(E I)_{\text {full }}=(E I)_{0}+\frac{\prod E A}{\sum E A}\left(\frac{h_{c}+h_{t}}{2}\right)^{2}$. Where $E$ is the elastic modulus, $I$ is the second moment of area, $A$ is the section area, $h$ is the section height, and the subscripts $c$ and $t$ represent concrete and timber, respectively.

\section{B.2. Moment capacity of HTC}

Moment capacity of the HTC section with full composite action in Table 3 is calculated using section analysis based on sections as shown in Fig. A2. For the sections with height of 160mm, the concrete depth $a=125 \mathrm{~mm}$, for the sections with height of $190 \mathrm{~mm}$, the concrete depth $a=155 \mathrm{~mm}$. 
In the section analysis, tensile strength of concrete is neglected, and the compressive behaviour of the concrete follows that defined in Eurocode 2 [28], as shown in Eq. (A2).

$$
\sigma=\frac{1.05 E_{c m} \frac{\varepsilon}{f_{c m}}-\left(\frac{\varepsilon}{\varepsilon_{c 1}}\right)^{2}}{1+\left(1.05 E_{c m} \frac{\varepsilon_{c 1}}{f_{c m}}-2\right) \frac{\varepsilon}{\varepsilon_{c 1}}} f_{c m}
$$

Where, $\mathrm{f}_{\mathrm{cm}}=43 \mathrm{MPa}$, based on the 28-days concrete cylinder test, $\mathrm{E}_{\mathrm{cm}}=34 \mathrm{GPa}, \varepsilon_{\mathrm{c} 1}=2.2 \%$, according to Eurocode 2.

Timber is assumed to be linear elastic with the properties of the $190 \times 35 \mathrm{~mm}$ MGP12 timber from AS1720.1 [27]. The elastic modulus is $12700 \mathrm{MPa}$, the characteristic tensile strength is $f_{c t}=12 \mathrm{MPa}$, with the coefficients of variation to be $C O V=25 \%$, the mean strength of timber can be calculated by Eq. (A3).

$$
f_{t}=\frac{f_{c t}}{1-1.645 C O V}
$$

In the section analysis, it is assumed that timber failure controls the ultimate failure, so the strain at timber bottom surface $\varepsilon_{\mathrm{t}}$ is the ultimate tensile strain of timber.

\section{References}

[1] Yeoh D, Fragiacomo M, De Franceschi M, Heng Boon K. State of the art on timber-concrete composite structures: literature review. J Struct Eng 2011;137:1085-95.

https://doi.org/10.1061/(ASCE)ST.1943-541X.0000353.

[2] Natterer J, Hamm J, Favre P. Composite wood-concrete floors for multi-story buildings. In: Gopu VKA, editor. International wood engineering conference. Sheraton New Orleans, New Orleans, Louisiana, USA: 1996. p. 431-5.

[3] Postulka J. Holz-beton-verbunddecken, 36 jahre erfahrung. Bautechnik 1997;74:478-9.

[4] Postulka J. Strengthening of wooden ceiling constructions. IABSE symposium strengthening of building structures-diagnosis and therapy. Venezia, Italy: 1983. p. 441-7.

[5] Fragiacomo M. Experimental behaviour of a full-scale timber-concrete composite floor with mechanical connectors. Mater Struct 2012;45:1717-35. http://dx.doi.org/10.1617/s11527-012-9869-3.

[6] Duwadi SR, Ritter MA. Timber bridges in the United States. Public Roads 1997;60:32-40.

[7] Cone CM. A composite timber-concrete bridge. New Zealand Timber Design Journal 1996;18:3-7.

[8] Rantakokko T, Salokangas L. Design of the Vihantasalmi Bridge, Finland. Struct Eng Int 2000;10:150-2. https://doi.org/10.2749/101686600780481590.

[9] Richart FE, Williams CB. Tests of composite timber and concrete beams. Engineering experiment station bulletin series. Urbana, Illinois, USA: University of Illinois; 1943.

[10] Ceccotti A. Composite concrete-timber structures. Prog Struct Eng Mater 2002;4:264-75. http://dx.doi.org/10.1002/pse.126. 
[11] Bathon L, Bletz O, Schmidt J. Hurricane proof buildings-an innovative solution using prefabricated modular wood-concrete-composite elements. 9th World Conference on Timber Engineering (WCTE 2006). Portland, Oregon, USA: 2006.

[12] Clouston P, Bathon LA, Schreyer A. Shear and bending performance of a novel wood-concrete composite system. J Struct Eng 2005;131:1404-12. https://doi.org/10.1061/(ASCE)07339445(2005)131:9(1404).

[13] Ceccotti A, Fragiacomo M, Giordano S. Long-term and collapse tests on a timber-concrete composite beam with glued-in connection. Mater Struct 2007;40:15-25.

http://dx.doi.org/10.1617/s11527-006-9094-z.

[14] Deam BL, Fragiacomo M, Gross LS. Experimental behavior of prestressed LVL-concrete composite beams. J Struct Eng 2008;134:801-9. http://dx.doi.org/10.1061/(ASCE)07339445(2008)134:5(801).

[15] Gutkowski RM, Brown K, Shigidi A, Natterer J. Laboratory tests of composite wood-concrete beams. Constr Build Mater 2008;22:1059-66. http://dx.doi.org/10.1016/j.conbuildmat.2007.03.013. [16] Lukaszewska E, Fragiacomo M, Johnsson H. Laboratory tests and numerical analyses of prefabricated timber-concrete composite floors. J Struct Eng 2010;136:46-55.

https://doi.org/10.1061/(ASCE)ST.1943-541X.0000080.

[17] Boccadoro L, Frangi A. Experimental analysis of the structural behavior of timber-concrete composite slabs made of beech-laminated veneer lumber. J Perform Constr Facil 2014;28:A4014006. https://doi.org/10.1061/(ASCE)CF.1943-5509.0000552.

[18] Martins C, Dias AMPG, Costa R, Santos P. Environmentally friendly high performance timberconcrete panel. Constr Build Mater 2016;102:1060-9.

https://doi.org/10.1016/j.conbuildmat.2015.07.194.

[19] Boccadoro L, Zweidler S, Steiger R, Frangi A. Bending tests on timber-concrete composite members made of beech laminated veneer lumber with notched connection. Eng Struct 2017;132:1428. https://doi.org/10.1016/j.engstruct.2016.11.029.

[20] Ceccotti A. Timber-concrete composite structures. In: Blass HJ, Aune P, Choo BS, Gorlacher R, Griffiths DR, Hilson BO, et al., editors. Timber engineering, step 2. 1st ed. Almere, The Netherlands: Centrum Hout; 1995. p. E13/1-E/2.

[21] Natterer J. Concepts and details of mixed timber-concrete structures. Composite constructionconventional and innovative. Innsbruck, Austria: 1997. p. 175-80. http://doi.org/10.5169/seals-964. [22] Clouston P, Schreyer A. Design and use of wood-concrete composites. Pract Periodical Struct Des Constr 2008;13:167-74. https://doi.org/10.1061/(ASCE)1084-0680(2008)13:4(167).

[23] Gattas JM, O'Dwyer ML, Heitzmann MT, Fernando D, Teng JG. Folded hybrid FRP-timber sections: concept, geometric design and experimental behaviour. Thin Wall Struct 2018;122:182-92. https://doi.org/10.1016/j.tws.2017.10.007.

[24] Fernando D, Teng JG, Gattas JM, Heitzmann M. Hybrid fibre-reinforced polymer-timber thinwalled structural members. Adv Struct Eng 2017:1-9. http://dx.doi.org/10.1177/1369433217739709. [25] Mainey AJ, Gilbert BP, Fernando D, Bailleres H. Thin-walled timber and FRP-timber veneer composite CEE-sections. In: Fernando D, Teng JG, Torero JL, editors. International Conference on Performance-based and Life-cycle Structural Engineering. Brisbane, Queensland, Australia: 2015. p. 1443-52. http://dx.doi.org/10.14264/uq1.2016.422.

[26] Fernando D, Frangi A, Kobel P. Behaviour of basalt fibre reinforced polymer strengthened timber laminates under tensile loading. Eng Struct 2016;117:437-56.

http://dx.doi.org/10.1016/j.engstruct.2016.03.009.

[27] AS1720.1. Timber structures part 1: design methods. Standards Australia Limited; 2010.

[28] CEN. Eurocode 2: design of concrete structures. Part 1-1: general rules and rules for buildings. London, UK: British Standards Institution; 2004.

[29] AS1012.9. Methods of testing concrete-compressive strength tests: concrete, mortar and grout specimens. Standards Australia Limited; 2014. 
[30] Miao C, Fernando D, Heitzmann MT, Bailleres H. GFRP-to-timber bonded joints: Adhesive selection. International Journal of Adhesion and Adhesives 2019;94:29-39.

https://doi.org/10.1016/j.ijadhadh.2019.05.007.

[31] AS/NZS 1748. AS/NZS 1748.1 Timber Solid Stress-graded for structural purposes General requirements: Standards Australia; 2011.

[32] Ou Y, Fernando D, Gattas JM. Novel hybrid FRP-timber-concrete floor panel system. 6th AsiaPacific conference on FRP in structures (APFIS-2017). Singapore: 2017.

[33] West System. Vacuum bagging techniques. In: West System Inc., editor. 7th ed. Bay City, MI USA: Gougeon Brothers; 2010.

[34] Confast. How to Install Concrete Wedge Anchors. 2007.

[35] CEN. EN 1995-1-1 Eurocode 5: Design of timber structures. Part 1-1: General - Common rules and rules for buildings: Brussels: BSI; 2004.

[36] Systèmes Dassault. Abaqus analysis user's guide (6.13). Abaqus 6.13. Providence, Rhode Island, United States: Simulia Corp; 2014.

[37] Forest Products Laboratory. Wood handbook : wood as an engineering material. Centennial edition ed. Madison, Wis: U.S. Dept. of Agriculture, Forest Service, Forest Products Laboratory; 2010.

[38] Saghafi H. Mechanical behavior of flat and curved laminates interleaved by electrospun nanofibers. Alma Mater Studiorum Università di Bologna; 2014.

[39] Hashin Z. Failure criteria for unidirectional fiber composites. J Appl Mech 1980;47:329-34. http://dx.doi.org/doi:10.1115/1.3153664.

[40] Garcia C, Trendafilova I, Zucchelli A, Contreras J. The effect of nylon nanofibers on the dynamic behaviour and the delamination resistance of GFRP composites. In: Manoach E, Stoykov S,

Wiercigroch M, editors. MATEC Web of Conferences. Sofia, Bulgaria: 2017.

https://doi.org/10.1051/matecconf/201814814001.

[41] Pilkey WD. Beams and Columns. In: Pilkey WD, editor. Formulas for Stress, Strain, and Structural Matrices: John Wiley \& Sons, Inc.; 2008. 


\section{List of Figures}

1. Design concept of the HTCC panels.

2. Design concept and dimensions of the HTCC panels: (a) cross section of conventional HTC panels, (b) cross section of HTCC panels, and (c) dimension of the proposed HTCC (unit: mm).

3. HTCC panel with core orientated transverse to the span.

4. Dimension of the HTCC panels with transverse core (unit: mm): (a) BC, (b) HC, and (c) SC types.

5. Fabrication process of the HTCC panels: (a) vacuum process for fabricating the core, (b) core attached to tensile timber, (c) preparation of concrete casting, (d) installed DynaBolts.

6. Test setup and instrumentation of specimens (unit: mm): (a) LC type, (b) BC and HC types, (c) SC type, and (d) digital image correlation system.

7. Load-displacement curves of tested specimens: (a) full response and (b) response in initial SLS region.

8. Failure modes of the specimens. (a)-(1): F1-F12.

9. Results for LC1P and LC2P specimens: (a) force-displacement response, (b) interfacial slipdisplacement curve, (c)-(e) failure modes.

10. Results for BC1P and BC2D specimens: (a) force-displacement response, (b) interfacial slipdisplacement curve, (c)-(h) BC1P failure modes, (i)-(j) BC2D failure modes.

11. Results for HC2D and SC2D specimens: (a) force-displacement response, (b) interfacial slipdisplacement curve, (c) HC2D failure modes, (d)-(f) SC2D failure modes.

12. DIC strain and through-depth sections for (a) BC, HC and SC core and (b) LC core.

13. Axial strain distribution through panel depth near mid-span: (a) section 1 in LC1P, (b)-(c) section 1 and 2 in HC1P, (d)-(e) section 1 and 2 in HC2D.

A1. A simply supported beam with four-point bending.

A2. Cross section, strain, and stress of the HTC panel section analysis. 


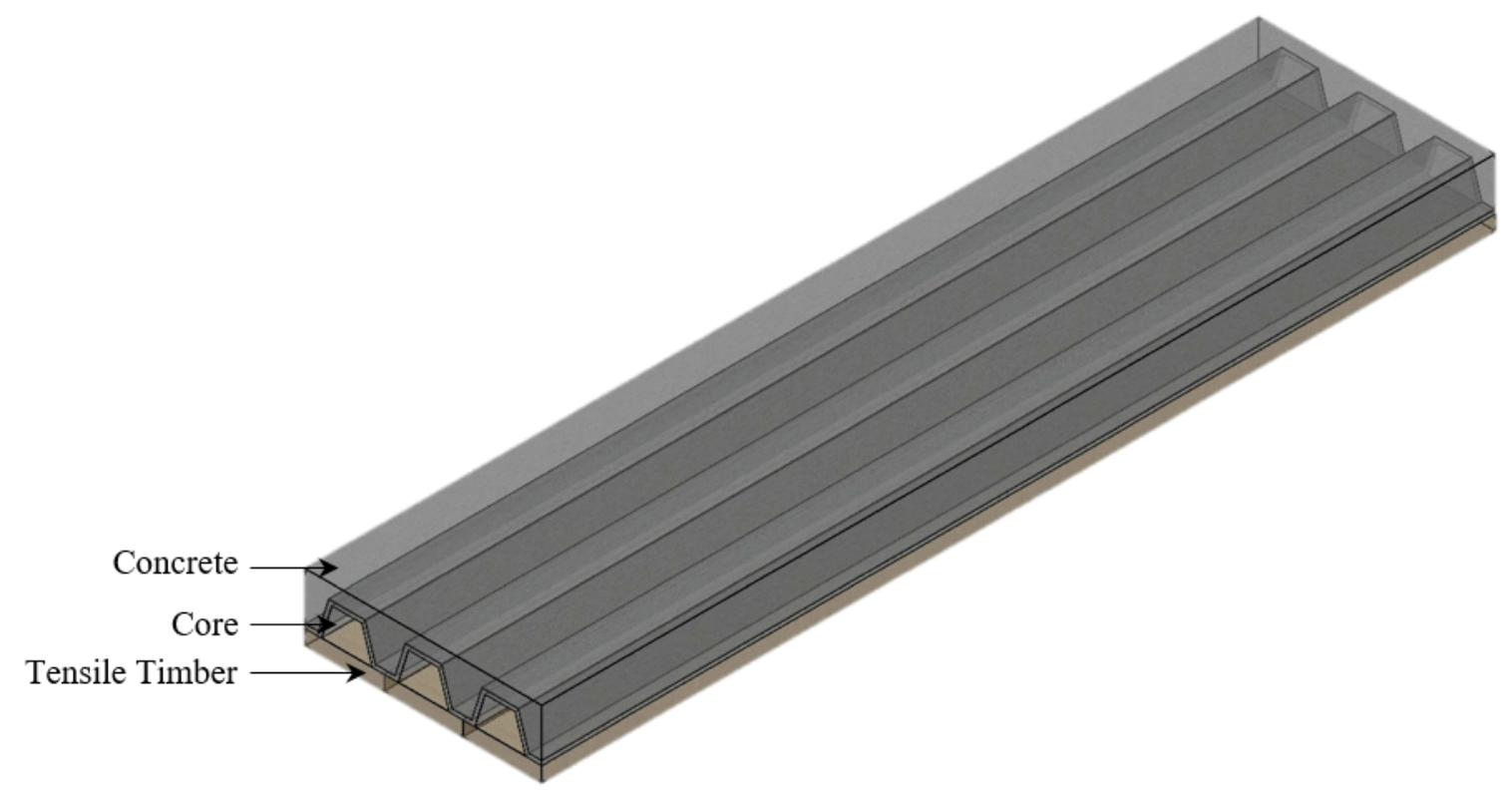

Fig. 1. Design concept of the HTCC panels. 
(a)

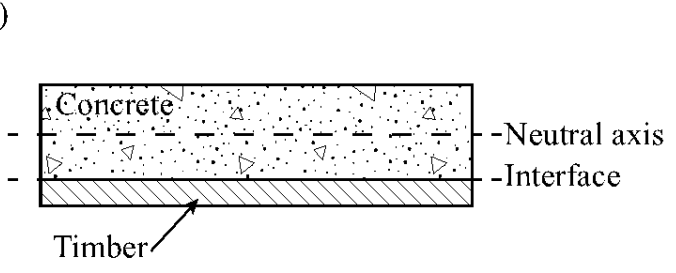

(b)

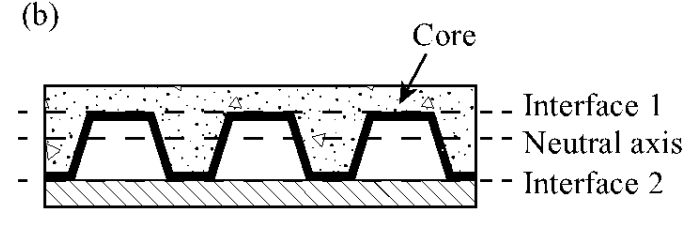

(c)

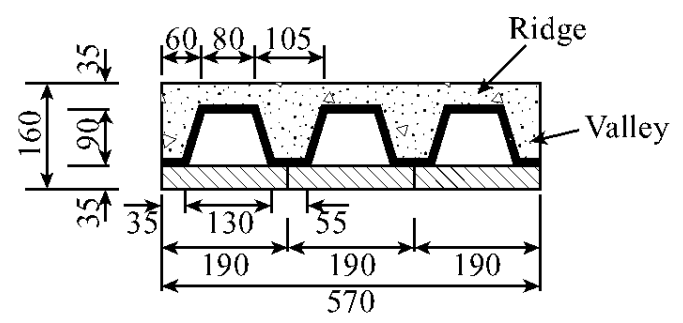

Fig. 2. Design concept and dimensions of the HTCC panels: (a) cross section of conventional HTC panels, (b) cross section of HTCC panels, and (c) dimension of the proposed HTCC (unit: mm). 


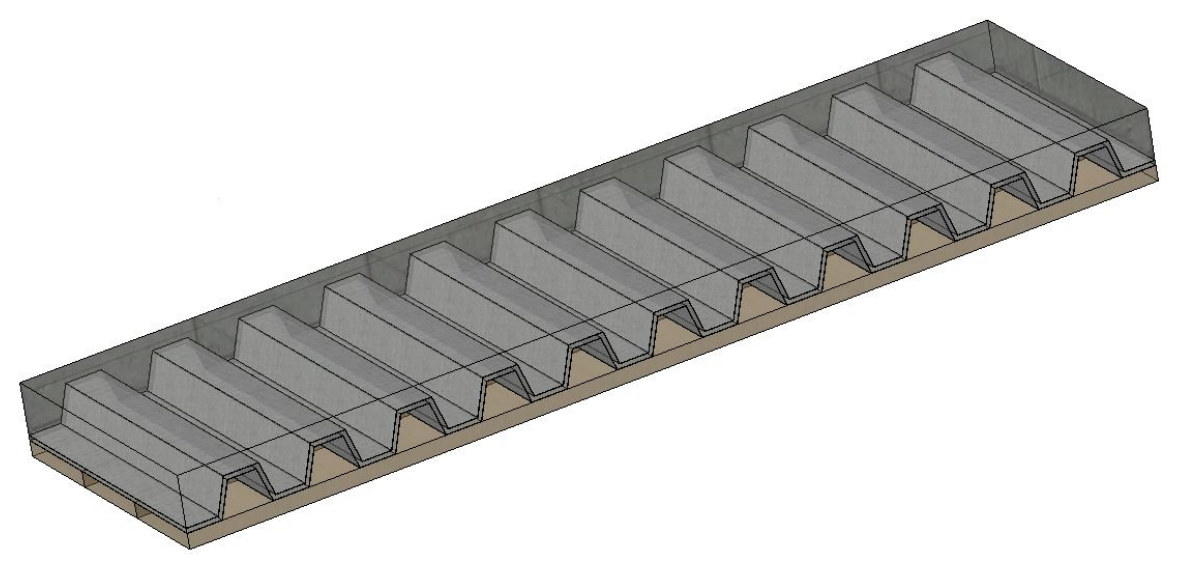

Fig. 3. HTCC panel with core orientated transverse to the span. 
(a)

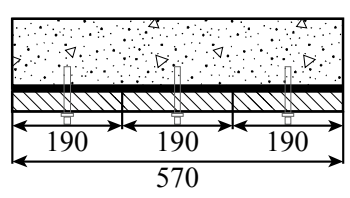

(b)

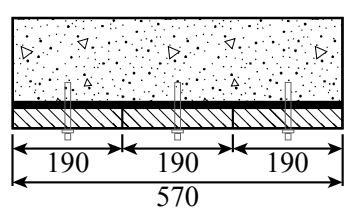

(c)

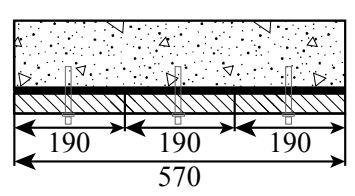

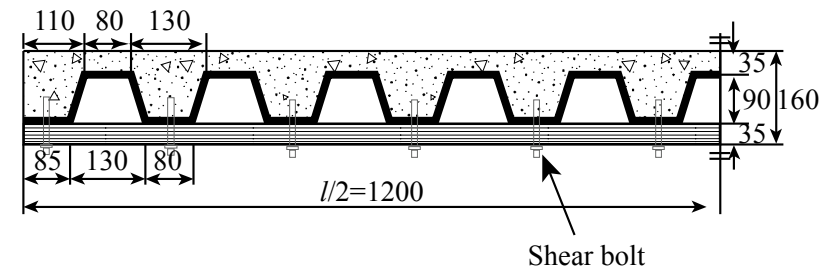
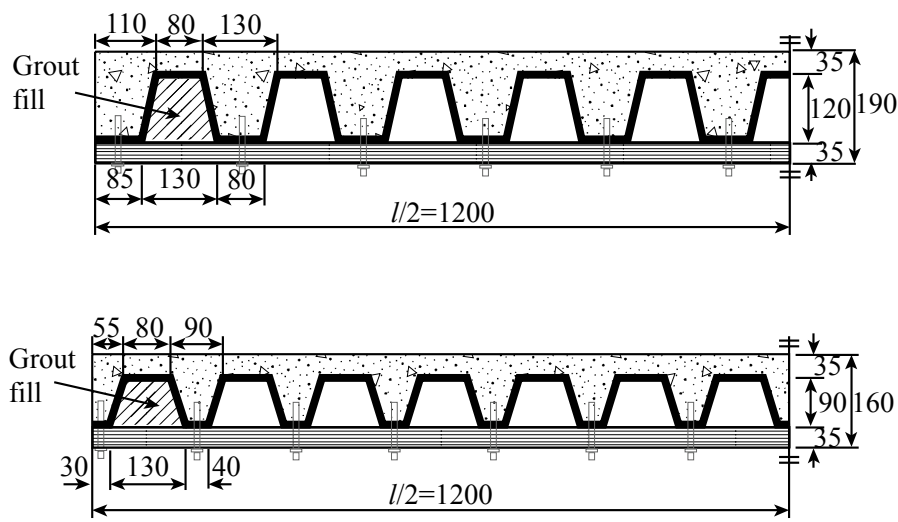

Fig. 4. Dimension of the HTCC panels with transverse core (unit: mm): (a) BC, (b) HC, and (c) SC types. 

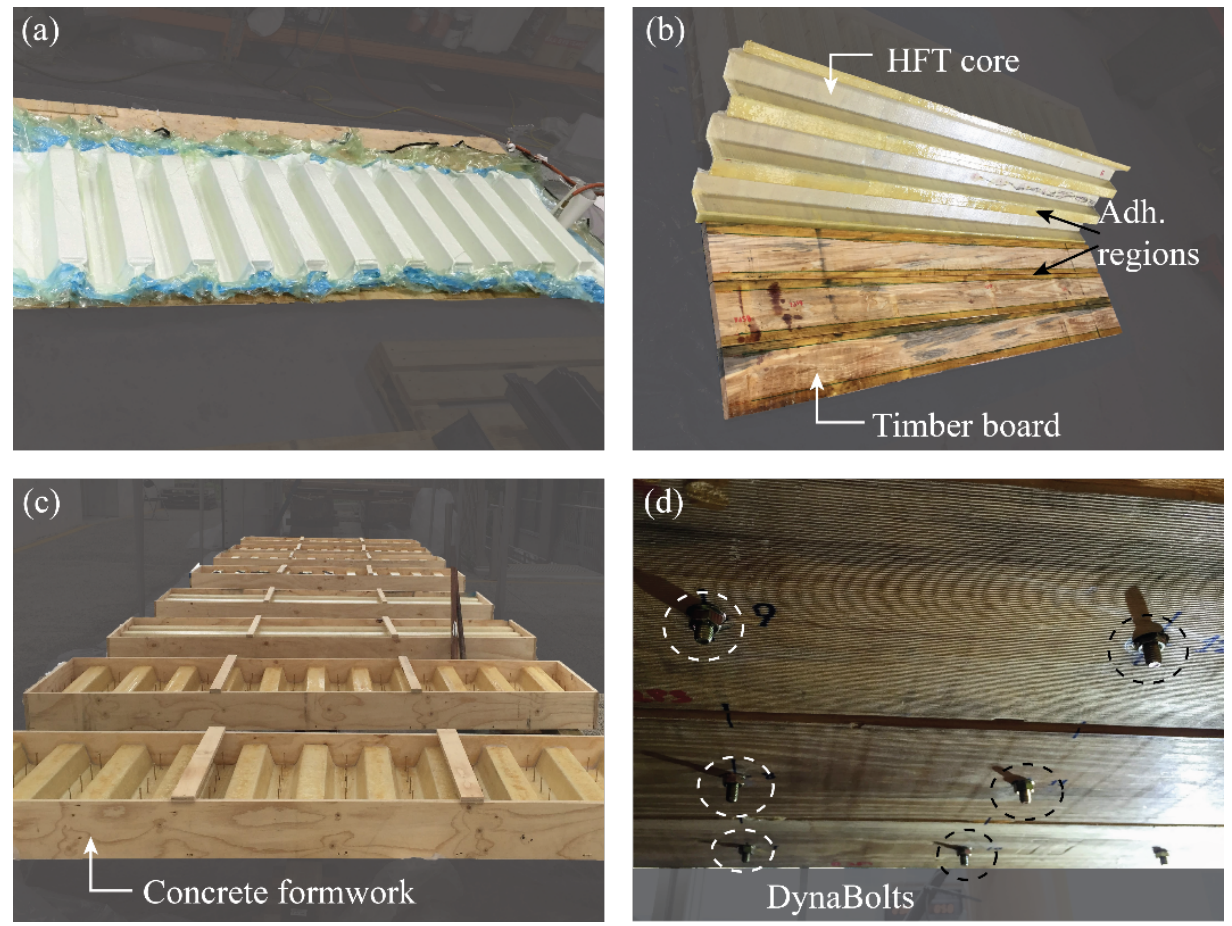

Fig. 5. Fabrication process of the HTCC panels: (a) vacuum process for fabricating the core, (b) core attached to tensile timber, (c) preparation of concrete casting, (d) installed DynaBolts. 
(a)

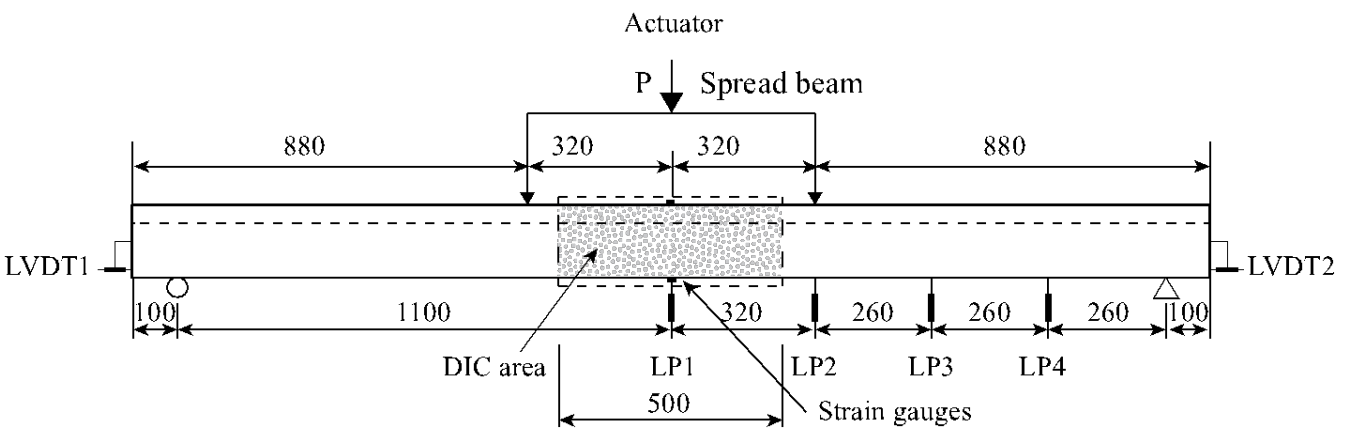

(b)

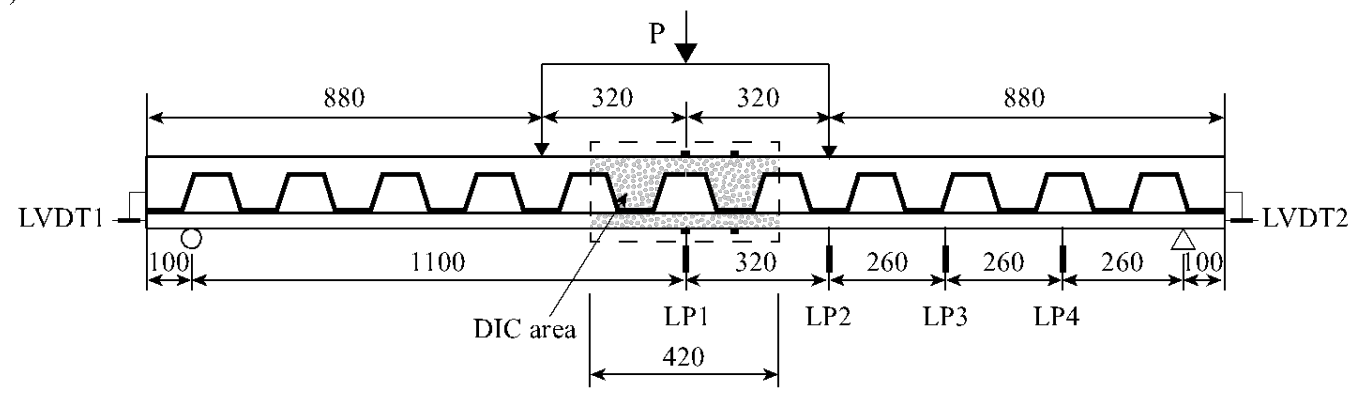

(c)

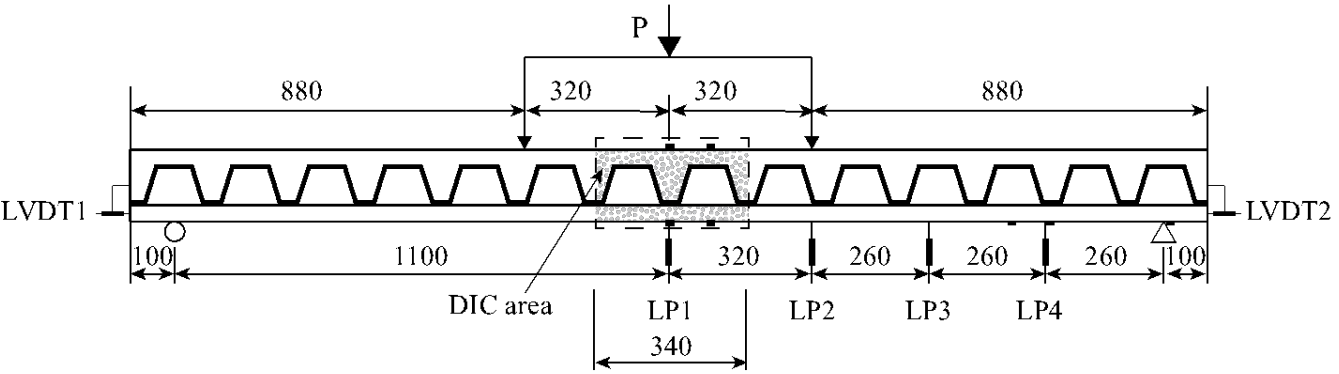

(d)

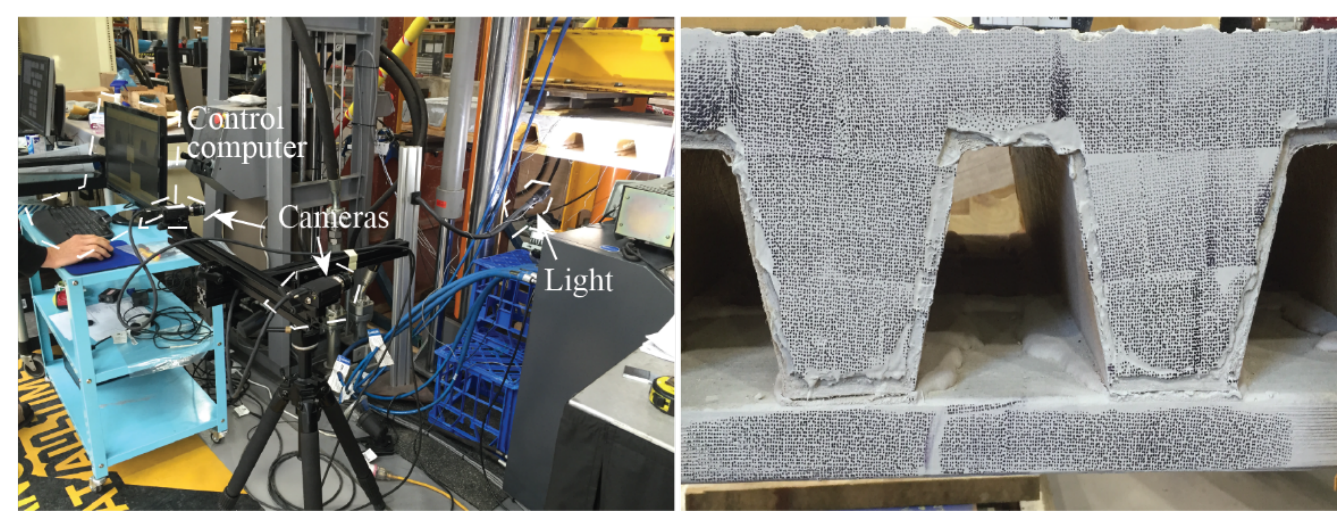

Fig. 6. Test setup and instrumentation of specimens (unit: mm): (a) LC type, (b) BC and HC types, (c) SC type, and (d) digital image correlation system. 


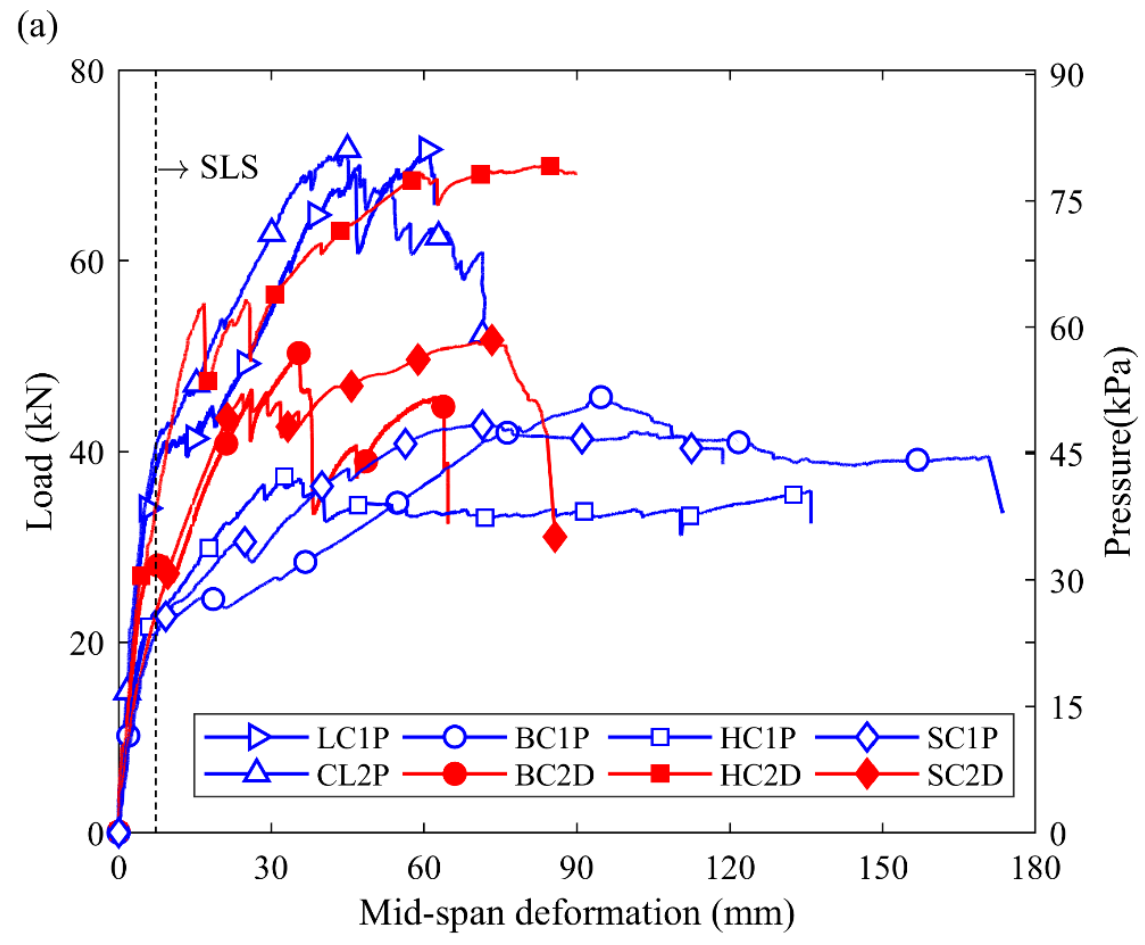

(b)

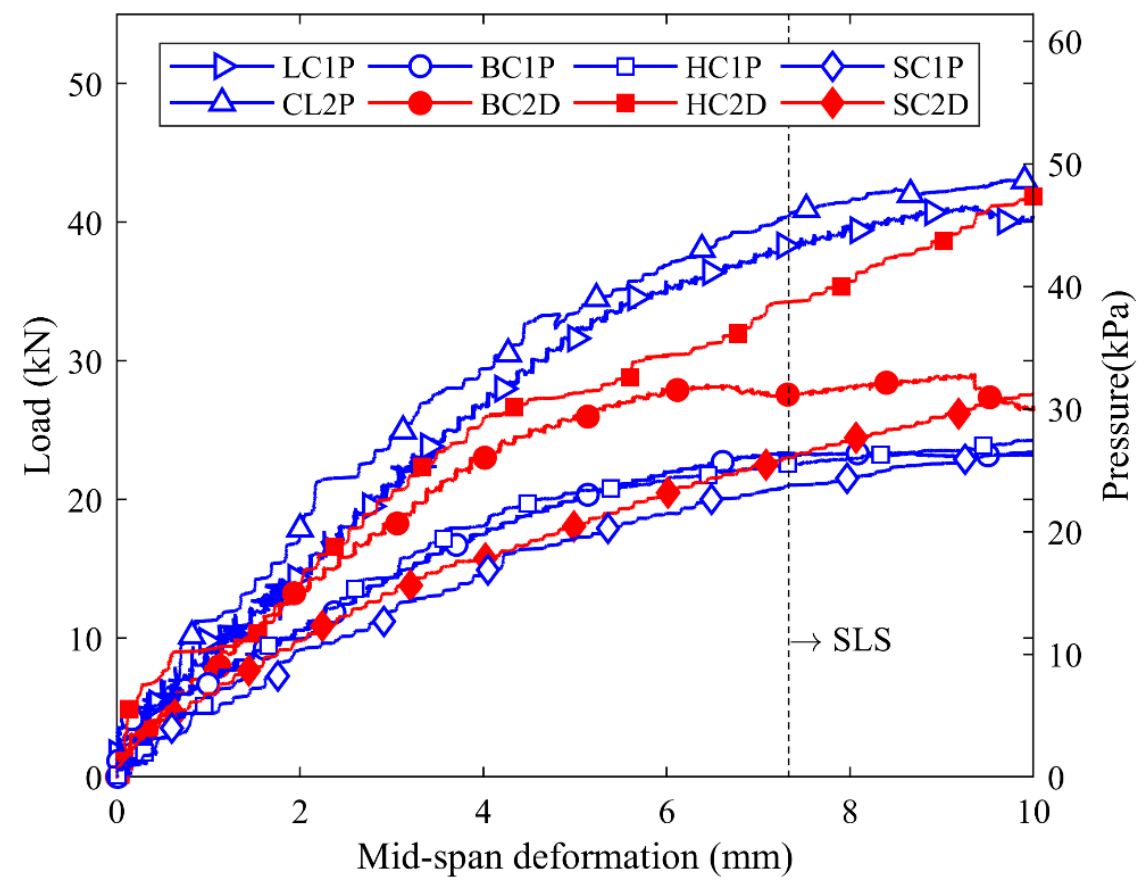

Fig. 7. Load-displacement curves of tested specimens: (a) full response and (b) response in initial SLS region. 

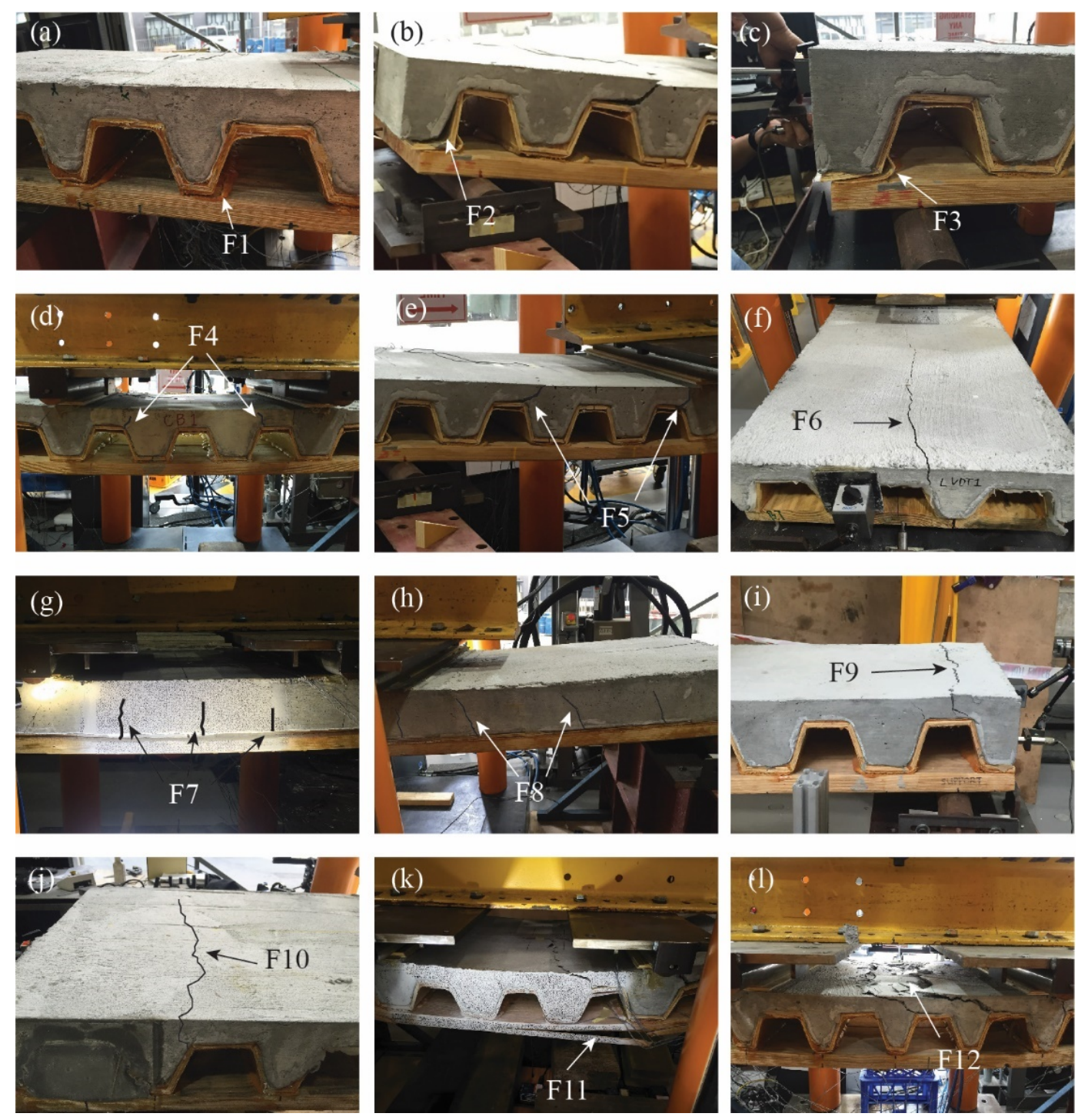

Fig.8. Failure modes of the specimens. (a)-(1): F1-F12. 

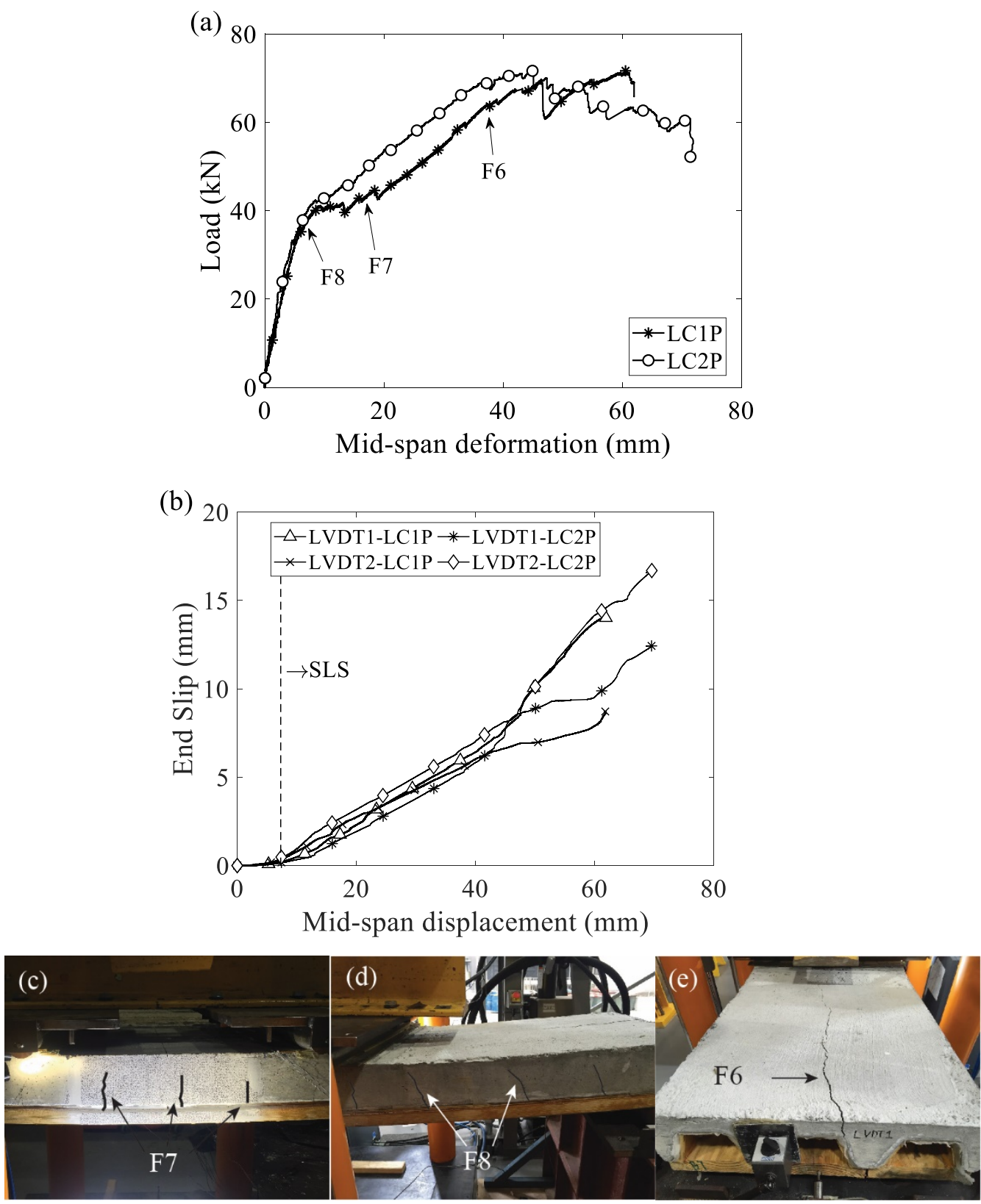

Fig. 9. Results for LC1P and LC2P specimens: (a) force-displacement response, (b) interfacial slipdisplacement curve, (c)-(e) failure modes. 

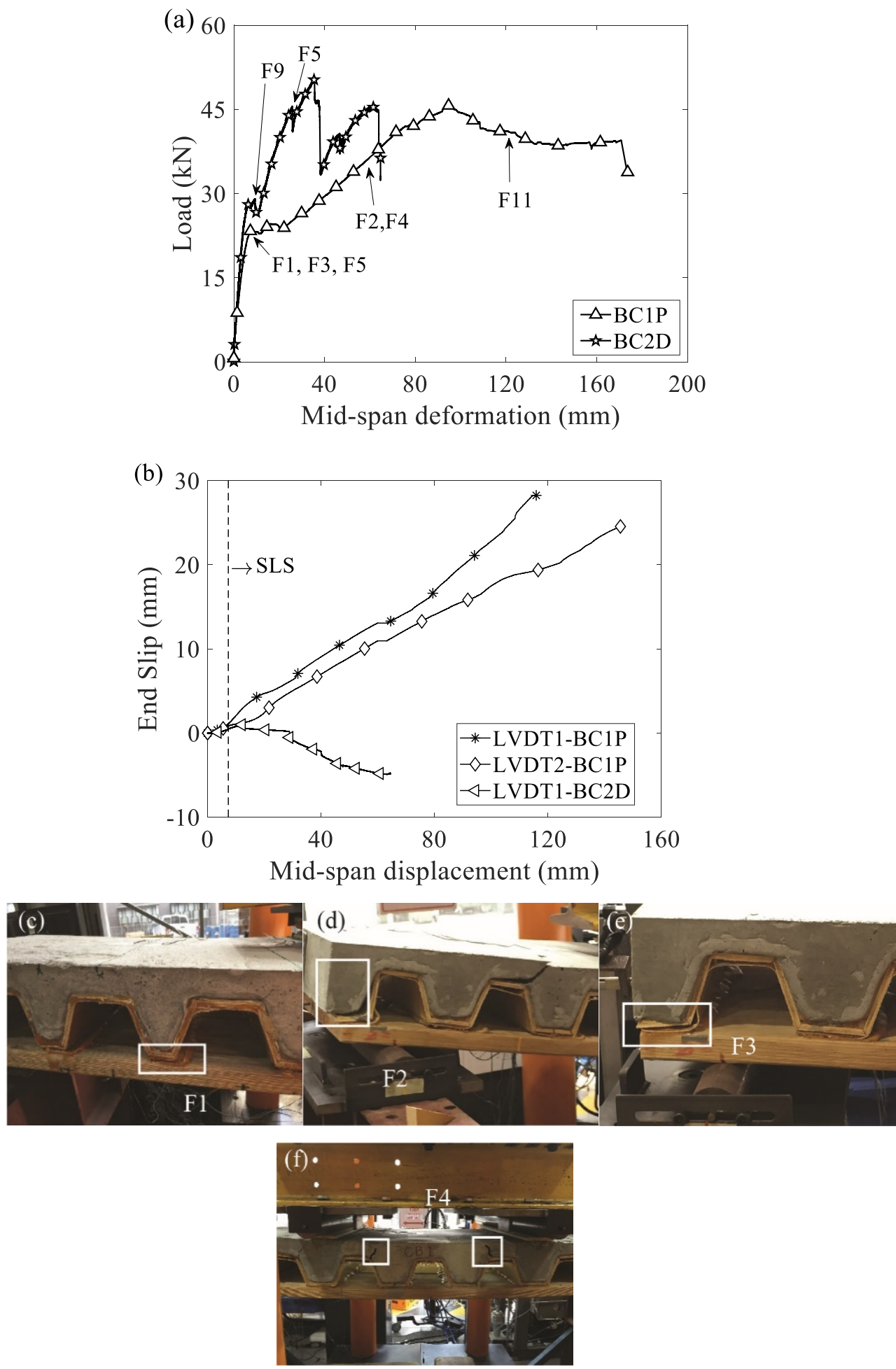

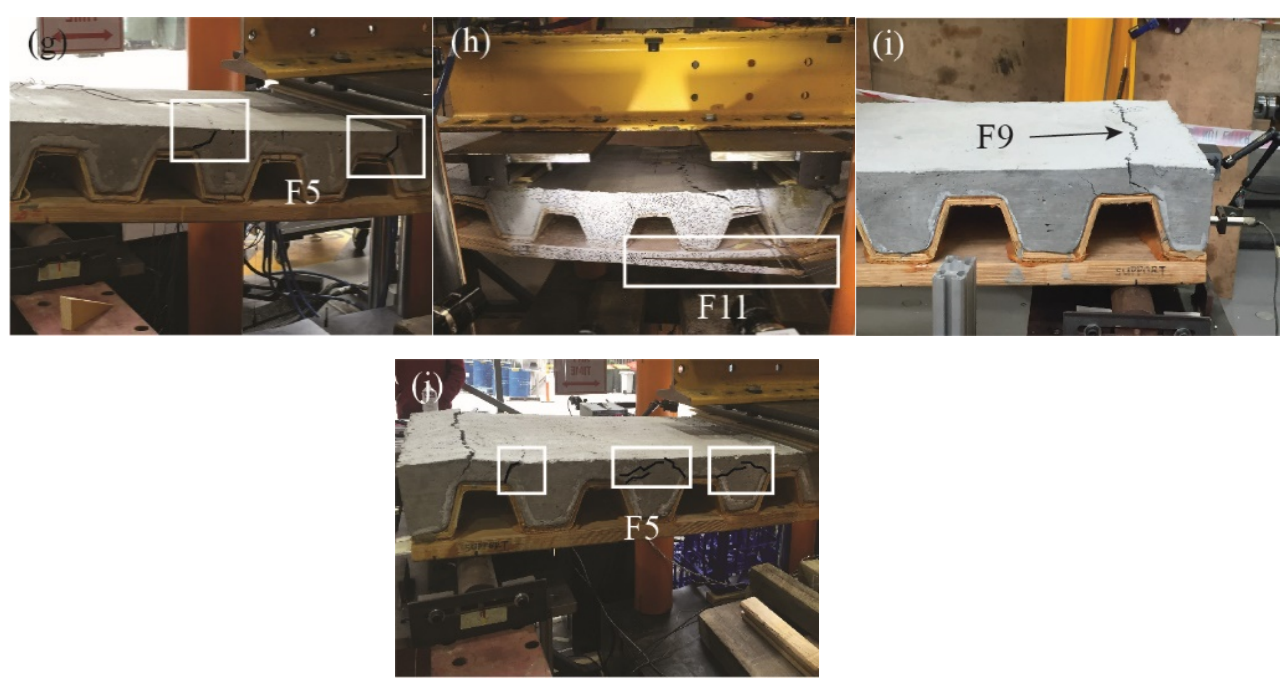

Fig. 10. Results for BC1P and BC2D specimens: (a) force-displacement response, (b) interfacial slip-displacement curve, (c)-(h) BC1P failure modes, (i)-(j) BC2D failure modes. 

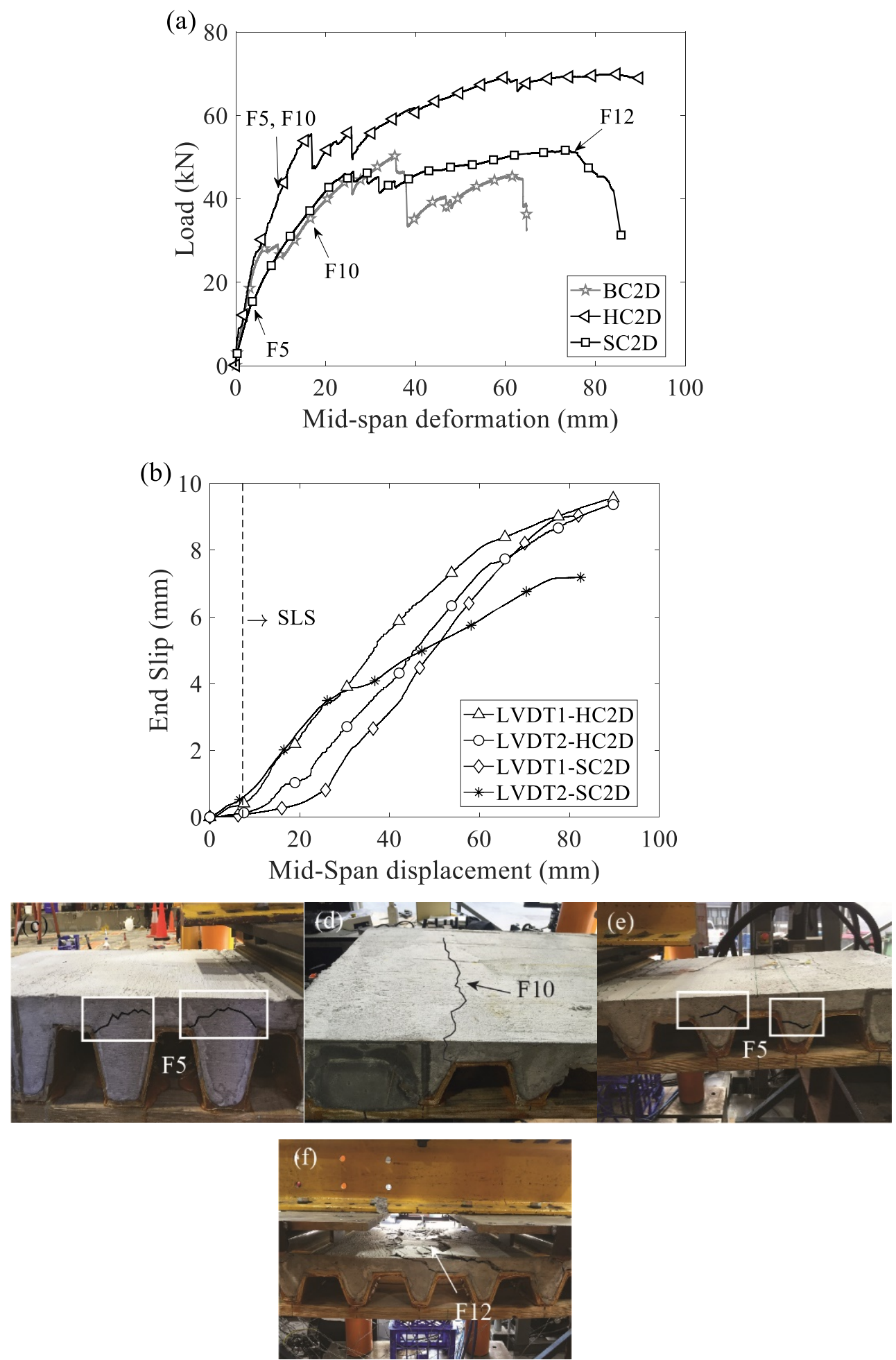

Fig. 11. Results for HC2D and SC2D specimens: (a) force-displacement response, (b) interfacial slip-displacement curve, (c) HC2D failure modes, (d)-(f) SC2D failure modes. 

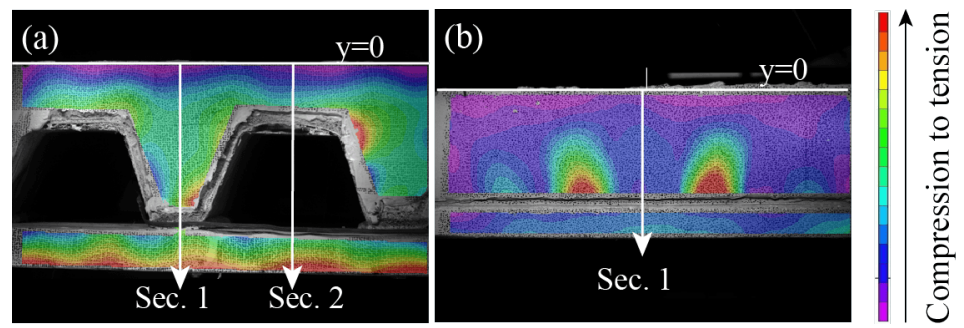

Fig. 12. DIC strain and through-depth sections for (a) BC, HC and SC core and (b) LC core. 
(a)

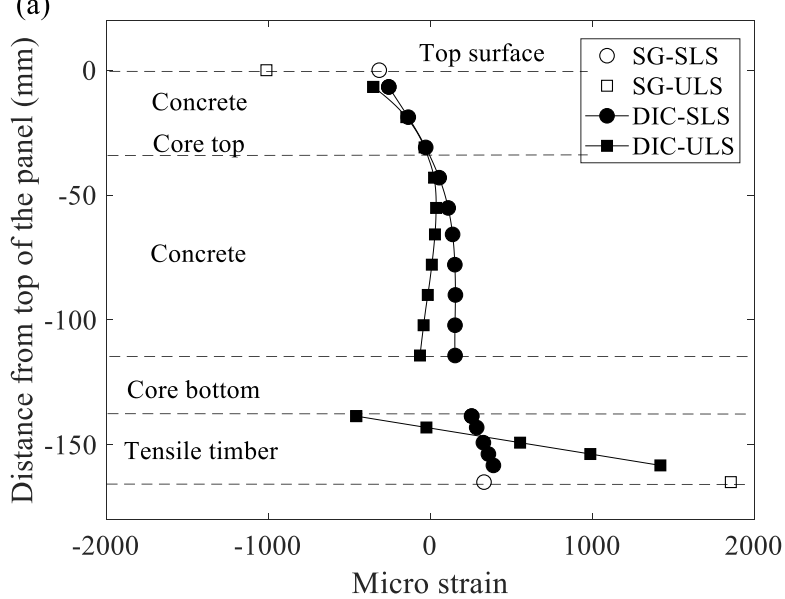

(b)
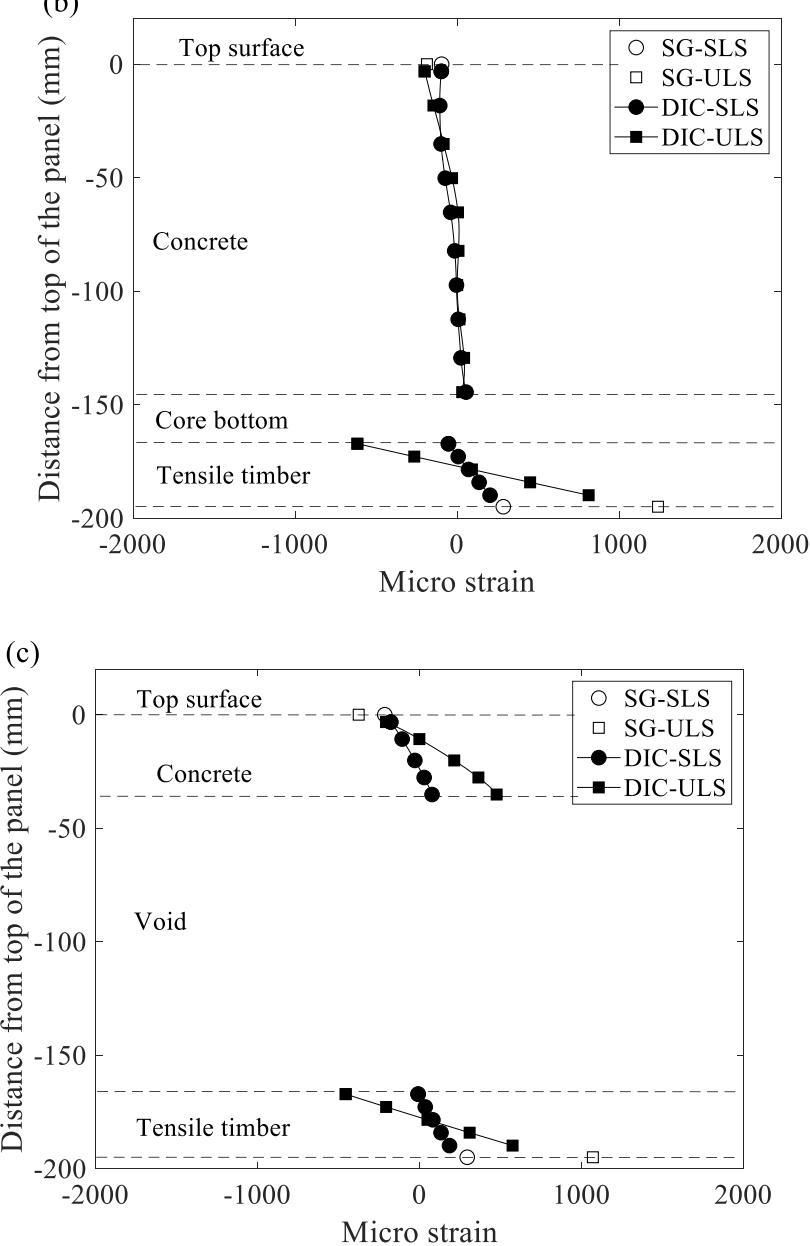

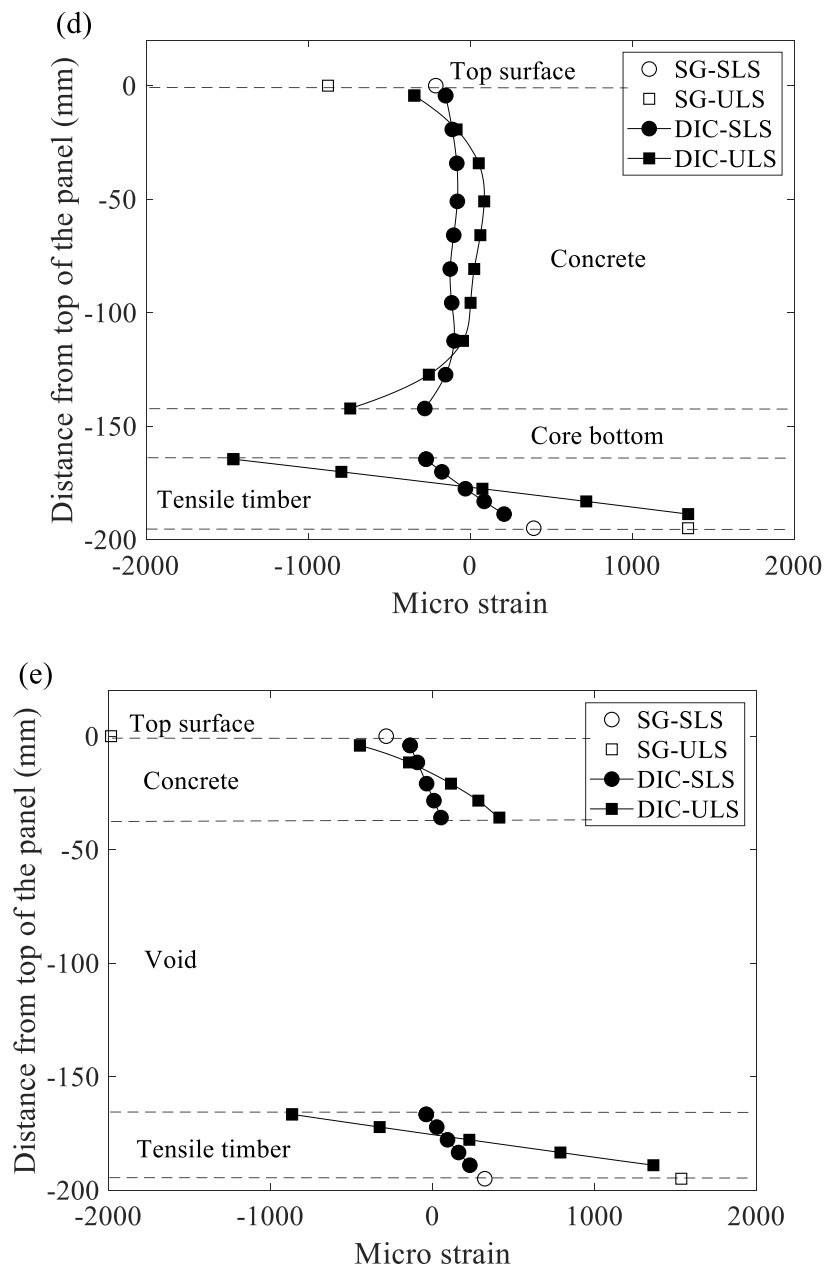

Fig. 13. Axial strain distribution through panel depth near mid-span: (a) section 1 in LC1P, (b)-(c) section 1 and 2 in HC1P, (d)-(e) section 1 and 2 in HC2D. 


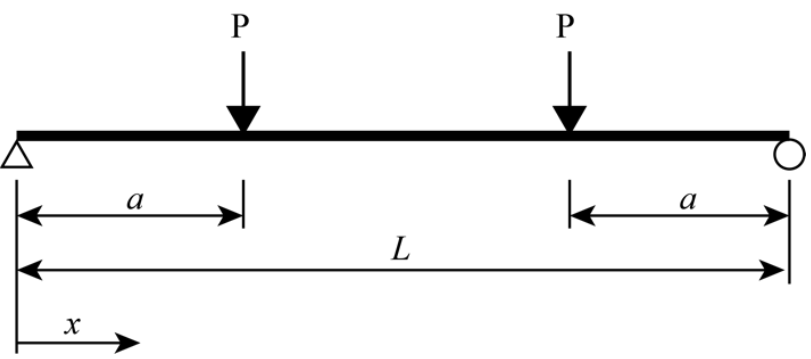

Fig. A1. A simply supported beam with four-point bending. 


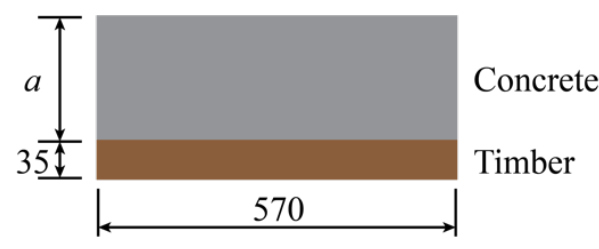

Cross section

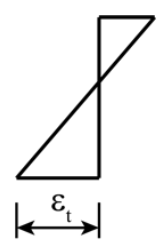

Strain

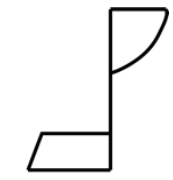

Stress

Fig. A2. Cross section, strain, and stress of the HTC panel section analysis. 